\title{
Chemical Modifications in Aggregates of Recombinant Human Insulin Induced by Metal-Catalyzed Oxidation: Covalent Cross-Linking via Michael Addition to Tyrosine Oxidation Products
}

\author{
Riccardo Torosantucci • Olivier Mozziconacci • Victor Sharov • Christian Schöneich • Wim Jiskoot
}

Received: 10 February 2012 / Accepted: 11 April 2012 / Published online: 10 May 2012

(C) The Author(s) 2012. This article is published with open access at Springerlink.com

\begin{abstract}
Purpose To elucidate the chemical modifications in covalent aggregates of recombinant human insulin induced by metal catalyzed oxidation (MCO).

Methods Insulin was exposed for $3 \mathrm{~h}$ at room temperature to the oxidative system copper(II)/ascorbate. Chemical derivatization with 4-(aminomethyl) benzenesulfonic acid (ABS) was performed to detect 3,4-dihydroxyphenylalanine (DOPA) formation. Electrospray ionization-mass spectrometry (ESI-MS) was employed to localize the amino acids targeted by oxidation and the cross-links involved in insulin aggregation. Oxidation at different $\mathrm{pH}$ and temperature was monitored with size exclusion chromatography (SEC) and ESI-MS analysis to further investigate the chemical mechanism(s), to estimate the aggregates content and to quantify DOPA in aggregated insulin.

Results The results implicate the formation of DOPA and 2amino-3-(3,4-dioxocyclohexa- |,5-dien-|-yl) propanoic acid $(\mathrm{DOCH})$, followed by Michael addition, as responsible for new cross-links resulting in covalent aggregation of insulin during $\mathrm{MCO}$. Michael addition products were detected between $\mathrm{DOCH}$ at positions Bl6, B26, Al4, and Al9, and free amino groups of the $\mathrm{N}$-terminal amino acids Phe $\mathrm{BI}$ and $\mathrm{Gly} \mathrm{Al}$, and side chains of Lys B29, His B5 and His B I0. Fragments originating from peptide bond hydrolysis were also detected.

Conclusion MCO of insulin leads to covalent aggregation through cross-linking via Michael addition to tyrosine oxidation products.
\end{abstract}

Electronic supplementary material The online version of this article (doi: | 0. I 007/s I 1095-0 |2-0755-z) contains supplementary material, which is available to authorized users.

R. Torosantucci $\cdot$ W. Jiskoot $(\triangle)$

Division of Drug Delivery Technology

Leiden/Amsterdam Center for Drug Research (LACDR)

Leiden University

P.O. Box 9502, 2300, Leiden, The Netherlands

e-mail:w.jiskoot@lacdr.leidenuniv.nl
KEY WORDS human insulin · oxidation · Michael addition . aggregation · fragmentation

$\begin{array}{ll}\text { ABBREVIATIONS } \\ \text { ABI } & \begin{array}{l}\text { ammonium bicarbonate } \\ \text { ABS }\end{array} \\ \text { CB } & \begin{array}{l}\text { sominomethyl) benzenesulfonic acid } \\ \text { DOCH }\end{array} \\ & \begin{array}{l}\text { 2-amino-3-(3,4-dioxocyclohexa- I,5-dien- I-yl) } \\ \text { propanoic acid }\end{array} \\ \text { DOPA } & \text { 3,4-dihydroxyphenylalanine } \\ \text { DTT } & \text { dithiothreitol } \\ \text { EDTA } & \text { ethylenediaminetetraacetic acid } \\ \text { ESI-MS } & \text { electrospray ionization-mass spectrometry } \\ \text { FT-ICR MS } & \text { Fourier transform ion cyclotron resonance } \\ & \text { mass spectrometry } \\ \text { HMWO } & \text { high-molecular-weight oligomers } \\ \text { IAM } & \text { iodoacetamide } \\ \text { MCO } & \text { metal catalyzed oxidation } \\ \text { PB } & \text { sodium phosphate buffer } \\ \text { SEC } & \text { size exclusion chromatography }\end{array}$

\section{INTRODUCTION}

During pharmaceutical production and storage, therapeutic proteins can be exposed to components that are able to induce
R. Torosantucci $\cdot$ O. Mozziconacci • V. Sharov $\cdot$ C. Schöneich Department of Pharmaceutical Chemistry

University of Kansas

2095 Constant Avenue

Lawrence, KS 66047, USA 
metal-catalyzed oxidation (MCO) (1), i.e. redox active transition metals, peroxides and reductants $(2,3)$. MCO of therapeutic proteins (4) such as recombinant human interferon alfa and recombinant human interferon beta has been reported to form highly immunogenic aggregates (5-7), providing evidence that protein oxidation can potentially lead to severe side reactions and loss of therapeutic effect. Furthermore, it has been shown that in diabetic complications (8), copper ion concentrations are higher than in normal subjects (9). Therefore, MCO is a potential cause of insulin degradation in vivo as well, when the production of reactive oxygen species (ROS) exceeds the endogenous antioxidant defense. Montes-Cortes et al. (10) showed that the carbonyl content of human insulin and the hydroxylation of phenylalanine, based on the formazan assay (11), is increased after exposure of insulin to the plasma of diabetic patients, which can contain high concentrations of oxidants (12). Moreover, in a recent paper we showed that MCO induces significant covalent aggregation of insulin in vitro (13). However, the underlying mechanisms of insulin aggregation through MCO are still unknown. Previous reports on the MCO of human insulin and glycated insulin indicate that both histidine residues are easily oxidized to 2-oxo histidine $(2,9)$.

Here we provide a more detailed analysis of the chemical modifications that occur during the $\mathrm{MCO}$ of recombinant human insulin, induced by $\mathrm{Cu}^{2+}$ and L-ascorbic acid as a representative electron donor (14-16), focusing on the amino acids that are modified and on the chemical mechanisms that lead to cross-linked insulin, as a consequence of the modifications in the primary structure. Since previous studies have demonstrated the presence of DOPA in proteins like cataractous lens proteins (17) and in atherosclerotic lesions (18), emphasis was placed on the detection of oxidation products arising from the four Tyr and the three Phe contained in insulin and, especially, on the formation of 2-amino-3-(3,4-dioxocyclohexa1,5-dien-1-yl) propanoic acid (DOCH), which constitutes a Michael acceptor for nucleophilic addition. Figure 1, panel a, displays the primary structure of insulin, the Glu-C digestion sites, the amino acids (in blue) with nucleophilic function, and the amino acids (in red) that can be oxidized to 3,4-dihydroxyphenylalanine (DOPA) and DOCH; Fig. 1b representatively illustrates the Michael addition on DOCH at position B16, and Fig. 1c shows the product of Michael addition on oxidized insulin. Complementary detection of DOPA and DOCH was achieved using mass spectrometry and fluorogenic tagging with 4 (aminomethyl)benzene sulfonic acid (ABS) (Scheme 1), according to the method reported recently by Sharov et al. $(19,20)$ Our results indicate that all aromatic amino acids of insulin, i.e. His, Tyr and Phe, are subject to MCO, predominantly yielding mono- and/or dihydroxylation products (or their respective oxidation products, i.e. DOCH from DOPA). Important for the mechanistic analysis of covalent protein aggregation, we detected cross-links between DOCH at positions B16, B26, A14, and A19 and free amino groups of the N- terminal amino acids Phe B1 and Gly Al, and the side chains of Lys B29, His B5 and His B10.

\section{MATERIALS AND METHODS}

\section{Materials}

Recombinant human insulin containing $0.4 \%$ (w/w) zinc was provided by Merck (Oss, The Netherlands). L-ascorbic acid, ethylenediaminetetraacetic acid sodium salt (EDTA), copper dichloride, arginine, monobasic and dibasic sodium hydrogen phosphate, ammonium bicarbonate (ABI), dithiothreitol (DTT), iodoacetamide (IAM) and the solvents glacial acetic acid and acetonitrile were purchased from Sigma-Aldrich (St.Louis, MO, USA). Millipore Q water was used for the preparation of all the formulations and solutions. All chemicals were of analytical grade and used without further purification. ABS was synthesized according to a published procedure (21). Glu-C endoproteinase used in this study was purchased from Promega (Madison, WI, USA). Centrifugal filter units with a volume capacity of $4 \mathrm{~mL}$ and a molecular weight cut-off of $3 \mathrm{kDa}$ were purchased from Millipore (Billerica, MA, USA). Cassette dialysis slides with a $2 \mathrm{kDa}$ cut-off were purchased from Thermo Scientific (Asheville, NG, USA).

\section{Metal-Catalyzed Oxidation of Insulin}

Insulin oxidation was performed at three $\mathrm{pH}$ values: $\mathrm{pH} 7.4$ in $50 \mathrm{mM}$ sodium phosphate buffer (PB), pH 3.0 in $50 \mathrm{mM}$ sodium citrate buffer $(\mathrm{CB})$ and at $\mathrm{pH} 8.0$ in $250 \mathrm{mM}$ ammonium bicarbonate $(\mathrm{ABI})$. For all the oxidation reactions, insulin was first dissolved in $0.1 \mathrm{M}$ hydrochloric acid and then diluted into the corresponding buffer. Depending on the desired $\mathrm{pH}$, $0.1 \mathrm{M}$ sodium hydroxide was used. When $\mathrm{CB}$ was used, the final $\mathrm{pH}$ of 3 was achieved without further addition of base. Insulin concentration was measured by UV spectroscopy using a molecular weight of $5.8 \mathrm{kDa}$ and an extinction coefficient of $6200 \mathrm{M}^{-1} \mathrm{~cm}^{-1}$ at $276 \mathrm{~nm}$ (22). Further dilutions in PB, ABI or $\mathrm{CB}$ were performed to obtain a final insulin concentration of $1 \mathrm{mg} / \mathrm{mL}$. Controls included $1 \mathrm{mg} / \mathrm{mL}$ of insulin in $50 \mathrm{mM} \mathrm{PB}, \mathrm{pH} 7.4$; in $50 \mathrm{mM} \mathrm{CB}, \mathrm{pH} 3.0$; and in $250 \mathrm{mM}$ ABI, pH 8.0. MCO was performed by addition to $1 \mathrm{~mL}$ of $1 \mathrm{mg} / \mathrm{mL}$ insulin, $100 \mu \mathrm{L}$ of $0.4 \mathrm{mM} \mathrm{CuCl}_{2}$ in $50 \mathrm{mM} \mathrm{PB}, \mathrm{pH}$ 7.4, or in $50 \mathrm{mM} \mathrm{CB}$, pH 3, or in $250 \mathrm{mM} \mathrm{ABI}$, pH 8, depending on the desired $\mathrm{pH}$, to a final concentration of $40 \mathrm{\mu M} \mathrm{CuCl}_{2}$. The reaction was performed in 2-mL Eppendorf tubes covered with aluminum foil to protect the reaction mixture from light. After $10 \mathrm{~min}$ of incubation of insulin with $\mathrm{Cu}^{2+}$, to allow copper to bind to insulin, the oxidation reaction was started by the addition of $110 \mu \mathrm{L}$ of $40 \mathrm{mM}$ L-ascorbic acid in $50 \mathrm{mM} \mathrm{PB}, \mathrm{pH} 7.4$, or in $50 \mathrm{mM} \mathrm{CB}$, pH 3, or in $250 \mathrm{mM}$ ABI, pH 8, depending on the desired $\mathrm{pH}$, to a final 
Fig. I (a) primary structure of human insulin with the Glu-C endoproteinase digestion sites. In blue are shown the nucleophilic amino acids which can be involved in Michael addition. In red the amino acids that can be oxidized to DOPA and DOCH. (b) Michael addition on oxidized human insulin. The amino group that initiates a nucleophilic reaction with the $\alpha, \beta$ unsaturated carbonyl compound $(\mathrm{DOCH})$, represents one of the nucleophilic amino acids of human insulin (in blue). (c) Product

of Michael addition on oxidized insulin.
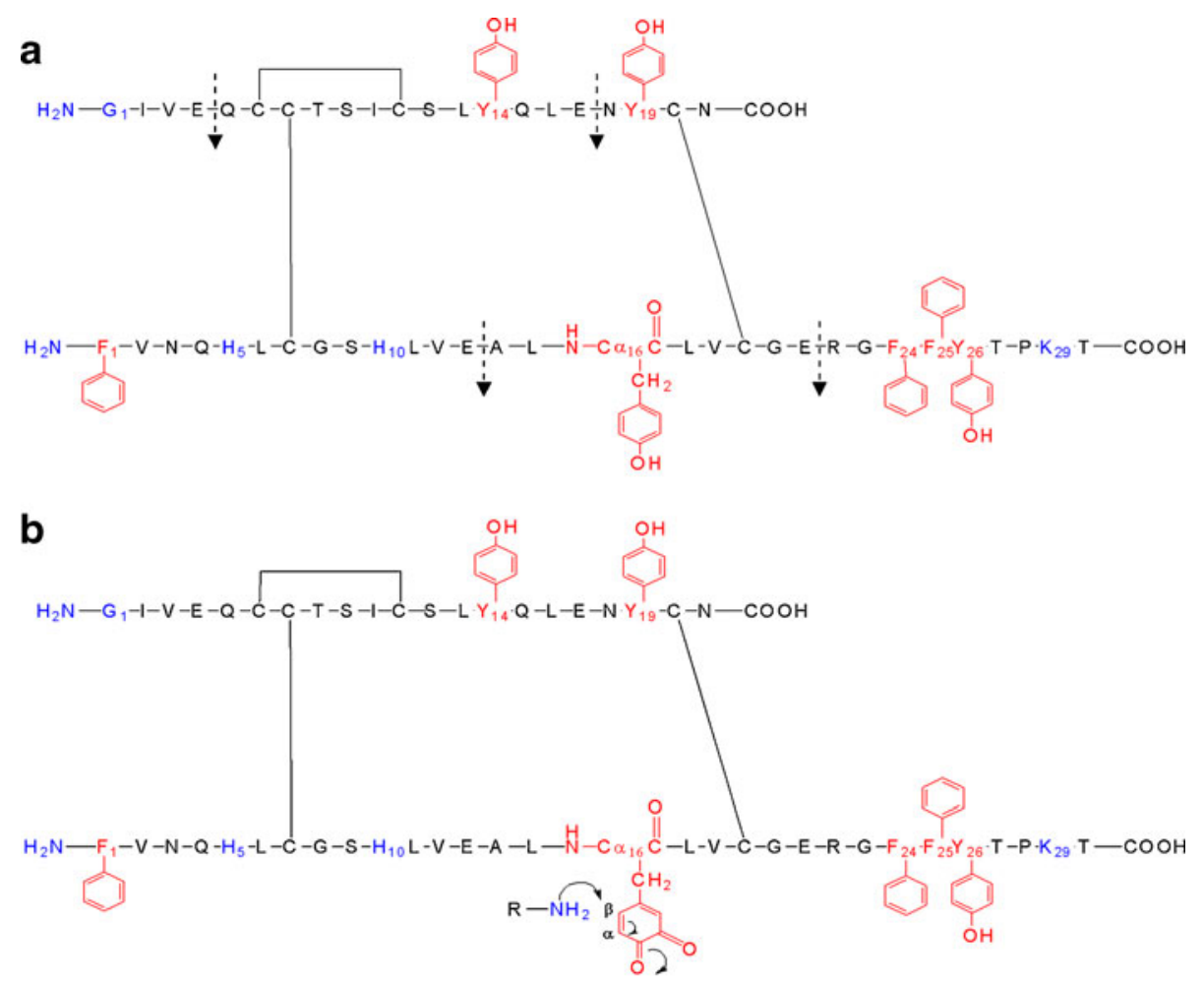

DOCH: 2-amino-3-(3,4-dioxocyclohexa-1,5dien-1-yl) propanoic acid

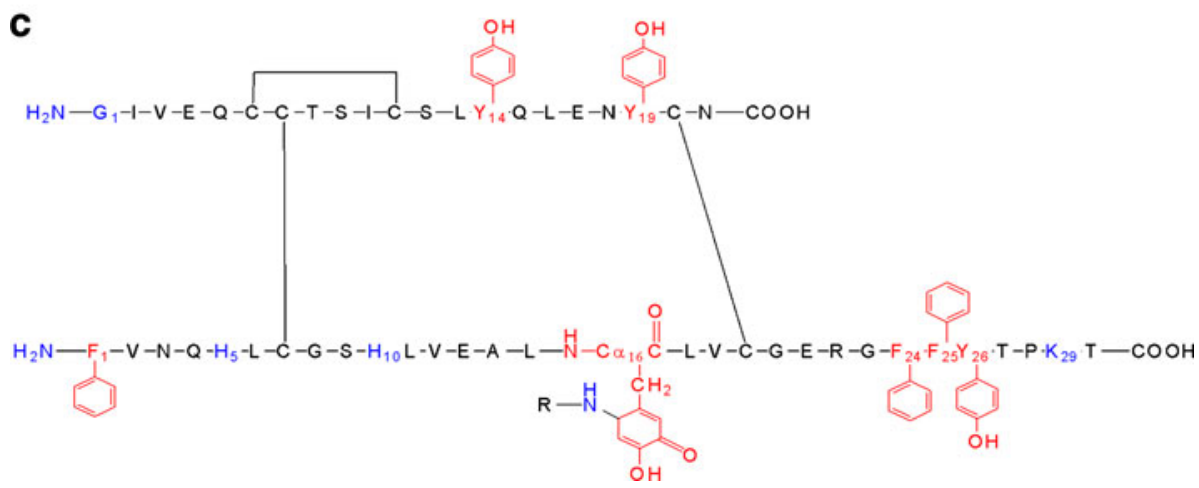

concentration of $4 \mathrm{mM}$. The reaction was quenched after $3 \mathrm{~h}$ of incubation at room temperature by adding $12.1 \mu \mathrm{L}$ of a $100 \mathrm{mM}$ EDTA in $50 \mathrm{mM} \mathrm{PB}, \mathrm{pH} 7.4$, or in $50 \mathrm{mM} \mathrm{CB}$, $\mathrm{pH} 3$, or in $250 \mathrm{mM} \mathrm{ABI}$, pH 8, depending on the desired $\mathrm{pH}$, to a final concentration of $1 \mathrm{mM}(15)$. To monitor the presence of protein fragments, the oxidation was also performed (in PB with the same amount of copper and L-ascorbic acid) at room temperature and at $37^{\circ} \mathrm{C}$ for $24 \mathrm{~h}$ before quenching. The oxidized samples were extensively dialyzed at $+4^{\circ} \mathrm{C}$ against $50 \mathrm{mM}$ ammonium bicarbonate (ABI) buffer, $\mathrm{pH}$ 8.0, for $24 \mathrm{~h}$. In another experiment, the oxidized sample in $50 \mathrm{mM}$ sodium citrate buffer $\mathrm{pH} 3$, was extensively dialyzed at $+4^{\circ} \mathrm{C}$ in
$50 \mathrm{mM}$ sodium phosphate buffer, $\mathrm{pH}$ 7.4, using centrifugal filter units. After that the sample was left to equilibrate for $12 \mathrm{~h}$ at room temperature.

\section{ABS-Derivatization of Undigested Samples}

Solutions of native insulin and insulin oxidized at pH 3.0 (in $\mathrm{CB}$ ) and pH 7.4 (in PB), dialyzed into $50 \mathrm{mM} \mathrm{ABI}$, were treated with $0.1 \mathrm{M}$ sodium hydroxide to a final $\mathrm{pH}$ of 9.0. Subsequently, to $100 \mu \mathrm{L}$ of these solutions, $11 \mu \mathrm{L}$ of a solution of $100 \mathrm{mM}$ ABS dissolved in water were added to a final concentration of $10 \mathrm{mM}$. Next, $1.1 \mu \mathrm{L}$ of $50 \mathrm{mM} \mathrm{K}{ }_{3} \mathrm{Fe}\left(\mathrm{CN}_{6}\right)_{6}$ dissolved in water 
<smiles>[R]c1ccc(O)c(O)c1</smiles>

DOPA

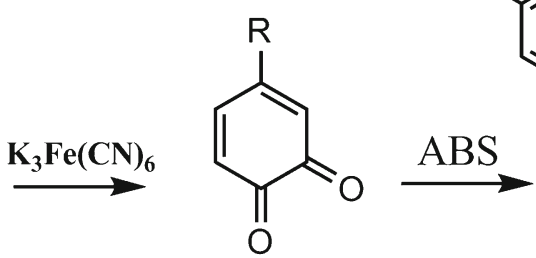

$\mathrm{DOCH}$

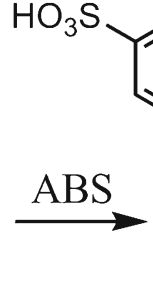

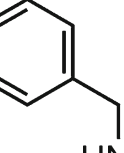

$\mathrm{HO}_{3} \mathrm{~S}$

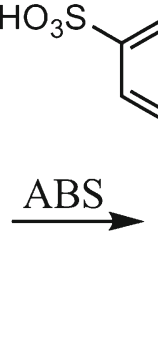

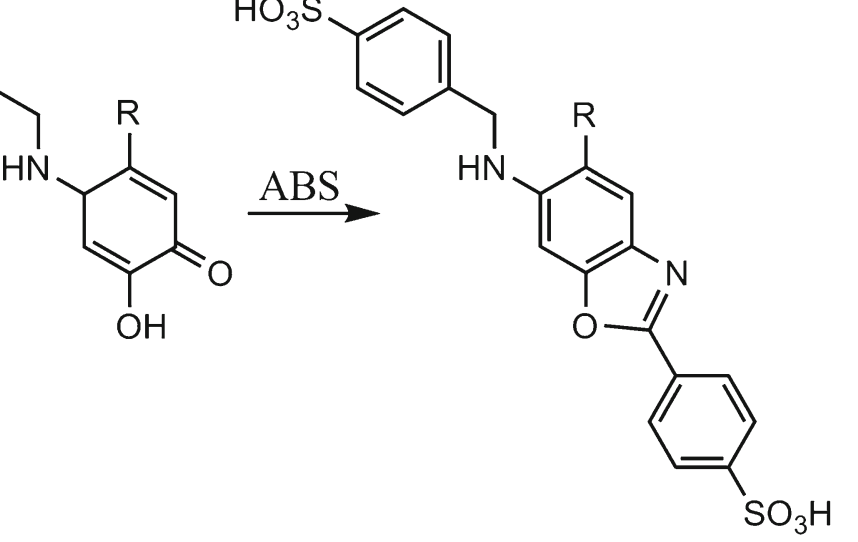

ABS:

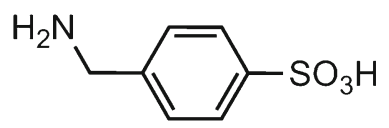

Scheme I Chemical derivatization of DOPA and DOCH with ABS.

was added to a final concentration of $0.5 \mathrm{mM}$. The reaction was conducted for $1 \mathrm{~h}$ at room temperature before performing SEC analysis. Controls for non-specific fluorescence included derivatization reagents (without protein) incubated under the same conditions and non-derivatized protein.

\section{Reduction, Alkylation and ABS-Derivatization of Insulin}

Solutions of native insulin and oxidized insulin, dialyzed into $50 \mathrm{mM}$ ABI, pH 8.0, were reduced using $50 \mathrm{mM}$ dithiothreitol (DTT), freshly prepared in $50 \mathrm{mM} \mathrm{ABI}, \mathrm{pH} 8.0$, added to a final concentration of $5 \mathrm{mM}$. The samples were incubated for $45 \mathrm{~min}$ at $45^{\circ} \mathrm{C}$ using a thermo heating bath (Thermo Scientific, Asheville, NC, USA). Subsequently, $200 \mathrm{mM}$ iodoacetamide (IAM), freshly prepared in $50 \mathrm{mM} \mathrm{ABI}, \mathrm{pH}$ 8.0, was added to a final concentration of $20 \mathrm{mM}$. The $\mathrm{pH}$ of $100 \mu \mathrm{L}$ of dialyzed, reduced and alkylated insulin samples was adjusted to 9.0 with $0.1 \mathrm{M}$ sodium hydroxide. Then, $11 \mu \mathrm{L}$ of a solution of $100 \mathrm{mM}$ ABS dissolved in water were added to a final concentration of $10 \mathrm{mM}$. Subsequently, $1.11 \mu \mathrm{L}$ of $50 \mathrm{mM} \mathrm{K}{ }_{3} \mathrm{Fe}$ $(\mathrm{CN})_{6}$ dissolved in water was added to a final concentration of $0.5 \mathrm{mM}$. The reaction was conducted for $1 \mathrm{~h}$ at room temperature before performing digestion with Glu-C.

\section{Glu-C Digestion}

The proteolytic digestion was performed after reduction, alkylation and ABS-derivatization of insulin, by incubating the samples with Glu-C endoproteinase in a ratio insulin: Glu-C endoproteinase 10:1 (w/w), overnight at $37^{\circ} \mathrm{C}$.

\section{Size-Exclusion Chromatography}

An Insulin HMWP column $(7.8 \times 300 \mathrm{~mm}$, Waters, Milford, MA, USA) was connected to a Shimadzu HPLG system
(UFLG Shimadzu Instrument equipped with two LC-20AT pumps, Columbia, MD) coupled to a photo-diode array detector (Shimadzu, SPD-M20A) and a fluorescence detector (Shimadzu, RF-20A). The photo diode array detector allowed for the recording of the UV spectrum in the region between 200-800 nm. Undigested insulin samples, without ABS treatment, were injected to calculate the percentages of the aggregates and to measure tyrosine fluorescence. Moreover, undigested insulin samples that were treated with ABS were injected to measure the benzoxazole fluorescence, which can be formed only in presence of DOPA and/or DOCH. The percentage of aggregates was calculated based on peak areas of the UV peaks at $276 \mathrm{~nm}$ (chromatograms not shown), as reported by Hermeling et al. $(5,6)$. The fluorescence detector was set at various different excitation (Ex) and emission (Em) wavelengths, depending on the type of analysis: Ex $275 \mathrm{~nm} /$ Em $302 \mathrm{~nm}$ was used for monitoring Tyr fluorescence and Ex 360/Em $490 \mathrm{~nm}$ was used for the detection of the benzoxazole fluorescence of the ABS-derivatized samples. The mobile phase was composed of a mixture of $1 \mathrm{~g} / \mathrm{L} \mathrm{L}$-arginine in water/acetonitrile/glacial acetic acid 65:20:15 (v/v/v) as reported in the United States and European pharmacopeias $(23,24)$. The elution buffer was freshly prepared, filtered using a regenerated cellulose filter (Sartorius Stedim Biotech, Arvada, $\mathrm{CO}$ ) and degassed prior to use.

\section{Steady-State Fluorescence Spectroscopy}

The benzoxazole fluorescence of the ABS-derivatized samples was measured upon excitation at $360 \mathrm{~nm}$. The emission spectra were recorded from $490 \mathrm{~nm}$ to $600 \mathrm{~nm}$ with a $5-\mathrm{nm}$ bandwidth on a Shimadzu RF-5000U spectrofluorometer. To monitor the presence of dityrosine, the non-derivatized, oxidized samples were analyzed after dialysis in $50 \mathrm{mM} \mathrm{ABI}, \mathrm{pH}$ 8.0, using an excitation wavelength of $315 \mathrm{~nm}$ and detection at $420 \mathrm{~nm}$ (25). 
After ABS-derivatization and dialysis, sample volumes were diluted with $50 \mathrm{mM}$ ABI to $0.5 \mathrm{~mL}$. Spectra were recorded in $0.5 \mathrm{~mL} 1$-cm light-pass fluorescence cuvettes (Hellma, Plainview, NY, USA). Controls for non-specific fluorescence included samples without a substrate or reagents incubated under the same conditions.

\section{Mass Spectrometry}

Digested and non digested peptides were analyzed by means of an LTQ-FT hybrid linear quadrupole ion trap Fourier transform ion cyclotron resonance (FT-ICR) mass spectrometer (Thermo-Finnigan, Bremen, Germany) (26) and a SYNAPT-G2 (Waters Corporation, Milford, MA), both located in the Mass Spectrometry Laboratory of the University of Kansas, under the conditions as described by Ikehata et al. (26). In short, peptides were separated on a reversed-phase LC Packings PepMap C18 column $(0.300 \times 150 \mathrm{~mm})$ at a flow rate $10 \mu \mathrm{L} / \mathrm{min}$ with a linear gradient from 0 to $65 \%$ acetonitrile in $0.06 \%$ aqueous formic acid over a period of $55 \mathrm{~min}$ using LC Packing Ultimate Chromatograph (Dionex). LCMS experiments were performed in a data-dependent acquisition manner using Xcalibur 2.0 software (Thermo Scientific). Five most intensive precursor ions in a survey MS1 mass spectrum acquired over a mass range of 300-2000 m/z were selected and fragmented in the linear ion trap by collisioninduced dissociation. The ion selection threshold was 500 counts. The MS/MS spectra obtained were analyzed with the software MassMatrix (27-30). MassMatrix was used to generate the theoretical fragment tables of the $b$ and $y$ ions of the different oxidized and cross-linked products. The theoretical fragments were compared to the experimental MS/MS spectra to validate the structures, which were taken into consideration only if the difference between the theoretical and the experimental $\mathrm{m} / \mathrm{z}$ of the parent ion (and the fragment ions) was strictly below 0.1 Da. The SYNAPT-G2 instrument was operated for maximum resolution with all lenses optimized on the $[\mathrm{M}+2 \mathrm{H}]^{2+}$ ion from the $[\mathrm{Glu}]^{1}$-fibrinopeptide B. The cone voltage was $30 \mathrm{~V}$ and Ar was admitted to the collision cell. The spectra were acquired using a mass range of $50-2000 \mathrm{~m} / \mathrm{z}$. The data were accumulated for $0.7 \mathrm{~s}$ per cycle. The CID data, at the $\mathrm{MS}^{2}$ level, acquired with the FT-ICR instrument were obtained after an attenuation of the parent ion of $35 \%$. The mass window to collect the parent ion was fixed to 0.1 Da. Deconvolution of the electrospray ionization data of the undigested insulin was obtained using the maximum entropy distribution algorithm implemented in the Masslynx MaxEnt software (Waters Corporation, Milford, MA) using an adduct of 1 proton. Assuming a normal statistical distribution of the noise, a uniform Gaussian with a width at half height of $0.5 \mathrm{Da}$ was used. A number of fifty iterations and a range between 0-36000 Da were used to build the most probable mass spectrum of the parent ions.

\section{RESULTS}

To guide the reader through the results, these will be presented in three sections: 1) Aggregation Profile of Oxidized Insulin and Elucidation of Aggregation Mechanism, 2) MS Analysis of Undigested Insulin Samples, and 3) Identification of Chemical Modifications by MS/MS Analysis of Reduced, Alkylated, ABS-Derivatized and Digested Samples.

\section{Aggregation Profile of Oxidized Insulin and Elucidation of Aggregation Mechanism}

Investigation of the chemical mechanisms, as well as the aggregation profile, was achieved with SEC. This technique was employed for several purposes: to detect and quantify the percentage of monomer loss, and the formation of covalent dimers and high-molecular-weight oligomers (HMWO) during MCO, by using UV detection at $276 \mathrm{~nm}$ (note that the composition of the mobile phase does not allow us to estimate the amount of non-covalent aggregates since these will be dissociated because of the organic solvent and the low $\mathrm{pH}$ of the eluent (31)); to monitor Tyr fluorescence in oxidized insulin, by using an excitation wavelength of $275 \mathrm{~nm}$ with emission set at $302 \mathrm{~nm}$, and to detect the development of DOPA and DOCH through derivatization with ABS. Furthermore, we used SEG to monitor the presence of fragments after prolonged oxidation. The percentages found (Table I) are in agreement with our previous results (13). MCO under our applied standard conditions leads to a loss of $25.6 \%$ of monomer and the formation of $18.8 \%$ of dimer and $6.8 \%$ of HMWO (Fig. 2a). The derivatization with $\mathrm{ABS}$, followed by SEC analysis, allowed the detection of DOPA and DOCH, in the monomer, as well as in the aggregates (Fig. 2b). The overall results point to the presence of $\mathrm{Tyr}$ and Phe oxidation products in all insulin species formed during MCO. A much weaker overall fluorescent signal was detected for the derivatized nonoxidized insulin (Fig. 2b), suggesting that a low percentage of DOPA was already present in the starting material, which could have been oxidized during production, storage and handling. The fluorescence spectra of the ABS derivatized samples (data not shown) were in agreement with the fluorescence detection performed with SEC: a low but measurable fluorescence emission was found for the native insulin derivatized with ABS and a 6-fold higher fluorescence signal was obtained for the oxidized insulin derivatized with ABS. Aggregated insulin was almost completely absent when MCO was performed at pH 3.0 (Fig. 2c). This result suggests that the aggregation process, which appears to be mediated by nucleophilic reactions with DOCH, is inhibited at lower $\mathrm{pH}$, likely due to protonation of free amino groups and His residues. Nevertheless, DOPA and DOCH were detected after derivatization with ABS (Fig. 2d), indicating 
Table I Percentages of Monomer, Dimer and High-Molecular-Weight Oligomers (HMWO) for the Insulin Oxidized Under Different Conditions and Native Insulin

\begin{tabular}{|c|c|c|c|}
\hline Sample & \%Monomer & \%Dimer & $\% \mathrm{HMWO}$ \\
\hline Oxidized insulin in PB, pH 7.4 & $74.4 \pm 0.9$ & $18.8 \pm 1.4$ & $6.8 \pm 1.2$ \\
\hline Oxidized insulin in $\mathrm{ABI}, \mathrm{pH} 8.0$ & $96.1 \pm 0.7$ & $3.9 \pm 0.7$ & $\mathrm{ND}^{a}$ \\
\hline Oxidized insulin in sodium citrate, $\mathrm{pH} 3$ & $99.2 \pm 0.3$ & $0.8 \pm 0.3$ & ND \\
\hline Oxidized insulin in sodium citrate, $\mathrm{pH}$ 3.0, spiked into PB, $\mathrm{pH} 7.4$ & $88.8 \pm 1.3$ & $9.3 \pm 1.1$ & $1.9 \pm 0.1$ \\
\hline Native insulin in PB, pH 7.4 & $99.4 \pm 0.2$ & $0.6 \pm 0.2$ & ND \\
\hline
\end{tabular}

Based on SEC analysis with UV detection at $276 \mathrm{~nm}$; data represent mean \pm standard deviation of 3 individual batches

${ }^{a} \mathrm{ND}=$ not detected

that the lower $\mathrm{pH}$ did not inhibit insulin oxidation. Hence, it may be possible that insulin oxidized at $\mathrm{pH} 3.0$ would still aggregate if the $\mathrm{pH}$ is increased after oxidation. To test this hypothesis, the buffer of the insulin sample oxidized at $\mathrm{pH}$ 3.0 was subsequently exchanged with $50 \mathrm{mM}$ sodium phosphate buffer, $\mathrm{pH} 7.4$, using centrifugal filter units. The sample was left to equilibrate for $12 \mathrm{~h}$ at room temperature before SEC analysis. Figure 2e and Table I represent the chromatograms and the percentages of aggregates for this experiment, displaying an increased amount of insulin dimer and trimer after the buffer change. Altogether these results indicate that Michael addition, the addition of a nucleophile to an $\alpha, \beta$-unsaturated carbonyl compound (32), may be the main mechanism of covalent insulin aggregation during MCO. Moreover, this experiment disproves a major role of S-S scrambling in insulin aggregation during MCO. However, the occurrence of non-covalent (besides covalent) aggregation cannot be fully excluded.

Additional evidence for Michael addition was provided in an experiment in which we performed the oxidation of insulin at $\mathrm{pH} 8.0$, in the presence of a relatively high concentration $(0.25 \mathrm{M})$ of ammonium bicarbonate. Under these conditions ammonia competes with nucleophilic functional groups of insulin (i.e. the $\mathrm{N}$-terminus of Gly $\mathrm{Al}$ and $\mathrm{Phe} \mathrm{B} 1$, and the side chains of His B5, B10 and Lys B29) for the addition to DOCH, thereby inhibiting aggregates formation, as shown in Fig. 3a and indicated by the low percentages of covalent aggregates measured (Table I). This was confirmed with FT-ICR MS analysis, performed on oxidized insulin in $\mathrm{ABI}$, after reduction, alkylation and Glu-C digestion. As can be seen in the chemical structure representatively depicted in Fig. 3b, two amino groups (highlighted in blue) are covalently bound to the first Phe residue and one amino group is covalently bound to the second Phe residue, indicating that Michael addition occurred between both oxidized Phe residues and ammonia originating from the buffer. These Michael addition products are generated by addition of the nucleophiles to the two $\beta$ type carbon atoms in the oxidation product $\mathrm{DOCH}$, and are consistent with the mass increases of the respective original Phe residues; however, due to the low abundance of sample we did not confirm the regiochemistry of nucleophile addition by NMR. The most relevant ions in the MS/MS spectra, which allow to confirm the addition of ammonia to $\mathrm{DOCH}$, are $\mathrm{b} 5^{+}, \mathrm{y} 6^{++}$and $\mathrm{y} 5^{+}$. The first, with $\mathrm{m} / \mathrm{z} 711.31$ of a singly charged ion, shows the sequence $\mathrm{G}_{\mathrm{B} 23} \mathrm{FFYT}_{\mathrm{B} 27}$ plus the additional molecular weight of three oxygen atoms and three ammonia molecules. These data suggest that the sequence PKT is neither oxidized, nor derivatized with amino groups. The doubly charged ion $\mathrm{y}^{++}$, with $\mathrm{m} / \mathrm{z} 394.6$, related to the sequence $\mathrm{F}_{\mathrm{B} 25} \mathrm{YTPKT}_{\mathrm{B} 30}$, shows that one oxygen and one ammonia molecule are incorporated into this sequence. Of course the Tyr residue could be the target for this incorporation; however, the ion $\mathrm{y}^{+}{ }^{+}$argues against this hypothesis where the singly charged ion with $\mathrm{m} / \mathrm{z} 609.32$ represents the unmodified sequence $\mathrm{Y}_{\mathrm{B} 26} \mathrm{TPKT}_{\mathrm{B} 30}$.

To evaluate the potential of MCO to induce fragmentation, already reported by other authors for the MCO of glycated insulin $(9,33)$, and by our group for the MCO of PEGylated insulin (13), human insulin was oxidized in $50 \mathrm{mM} \mathrm{PB}, \mathrm{pH} \mathrm{7.4,} \mathrm{for} 24 \mathrm{~h}$ at room temperature and $37^{\circ} \mathrm{C}$. Figure $2 \mathrm{f}$ clearly shows the elution of species after the monomer peak, which indicates the formation of lower molecular weight species.

\section{MS Analysis of Undigested Insulin Samples}

The FT-ICR MS analysis presented in this section was performed on oxidized insulin and native insulin (our control), prior to reduction, alkylation, ABS-derivatization and digestion with Glu-C. This analysis was executed to monitor the formation of oxidized monomers and to confirm the MCOinduced fragmentation, as well as to quantify these species relative to native insulin.

\section{Oxidation}

Human insulin contains three Phe and four Tyr residues. Oxidation of Phe to DOPA would require the incorporation of two 

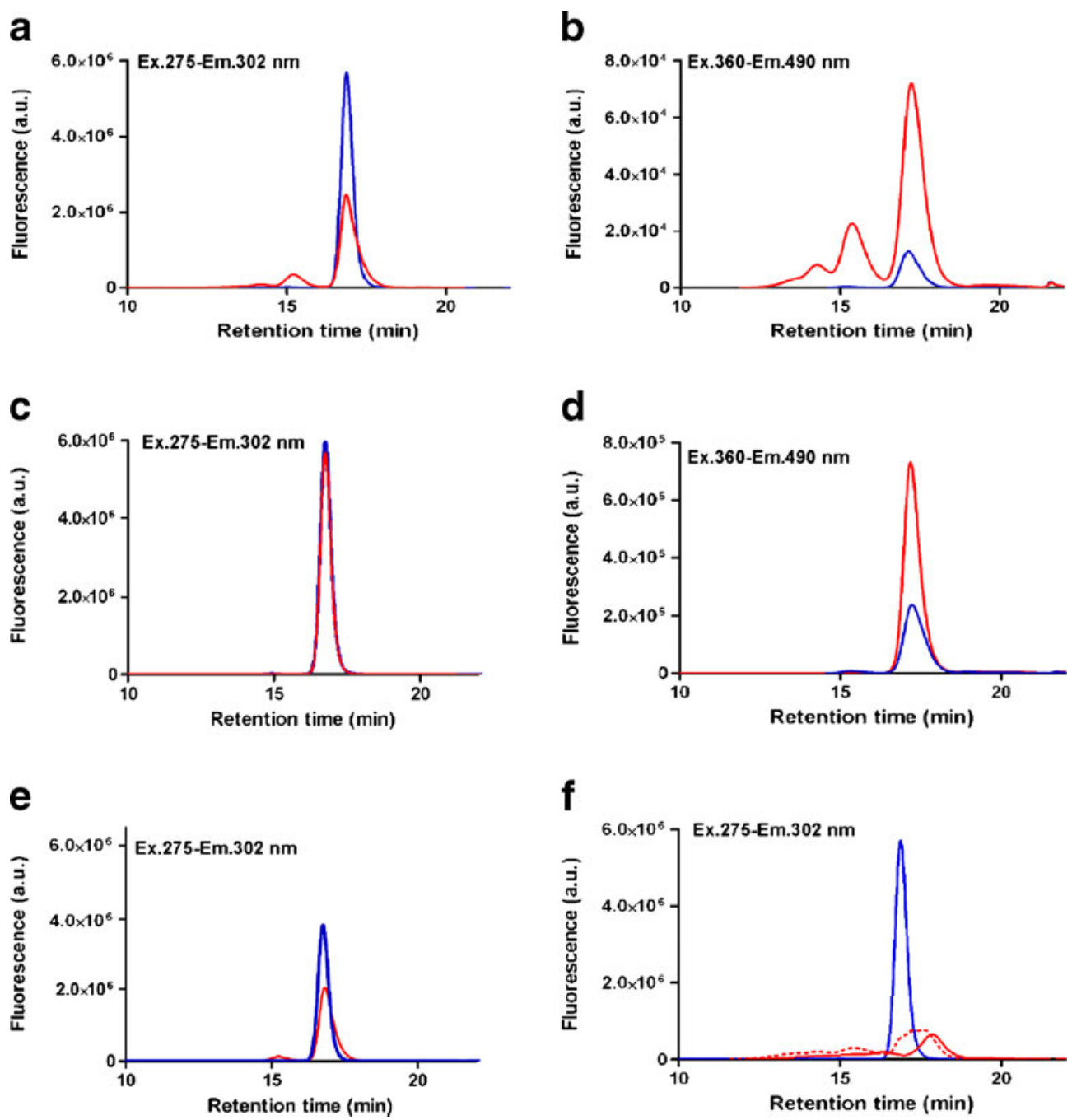

Fig. 2 SEC with intrinsic tyrosine fluorescence detection (a, c, e, f; Ex $275 \mathrm{~nm}-\mathrm{Em} 302 \mathrm{~nm}$ ) and ABS fluorescence detection (b, d): (a) insulin oxidized in $\mathrm{PB} 50 \mathrm{mM}, \mathrm{pH}$ 7.4, for $3 \mathrm{~h}$ at room temperature (in red) and its control, untreated insulin (in blue); (b) oxidized insulin ( $\mathrm{pH}$ 7.4), derivatized with ABS (in red) and its control, untreated insulin derivatized with $\mathrm{ABS}$ (in blue); (c) insulin oxidized in $50 \mathrm{mM}$ sodium citrate, $\mathrm{pH} 3.0$, for 3 h at room temperature (in red) and its control, untreated insulin (in blue); (d) oxidized insulin ( $\mathrm{pH}$ 3.0), derivatized with ABS (in red) and its control, untreated insulin derivatized with ABS (in blue); (e) insulin oxidized in $50 \mathrm{mM}$ sodium citrate, $\mathrm{pH}$ 3.0, for $3 \mathrm{~h}$ at room temperature, exchanged in $50 \mathrm{mM} \mathrm{PB}, \mathrm{pH} 7.4$, for $12 \mathrm{~h}$ at room temperature (in red) and its control, oxidized insulin ( $\mathrm{pH}$ 3) (in blue); (f) insulin oxidized in $50 \mathrm{mM} \mathrm{PB}, \mathrm{pH} 7.4$, for 24 h, at room temperature (dotted red line) and at $37^{\circ} \mathrm{C}$ (solid red line), untreated insulin (blue line).

oxygen atoms. Instead, oxidation of Tyr to DOPA would be represented by the incorporation of one oxygen atom. Hence, it should be possible to detect mass increases corresponding to ten atoms of oxygen per monomer, considering DOPA as oxidation product of Phe and Tyr. Based on this number, after deconvoluting each MS spectrum by using the maximum entropy distribution algorithm (Fig. 4), we added up the intensities observed for all monomers containing additional oxygen atoms $(\mathrm{n}=0-10)$ (i.e., for the masses $5,804.63+16,5804.63+32+\ldots+$ $5,804.63+160 \mathrm{Da})$. The resulting intensity of oxidized monomer in insulin exposed to MCO was found to be $\sim 300$ fold higher than that in non-oxidized insulin (Fig. 5), suggesting that the amount of insulin monomer containing oxygen had increased dramatically after MCO. These calculations are possible because after deconvolution of the mass-to-charge ratios, the absolute intensity of each ion is conserved. For better clarity, the oxidized monomer in insulin exposed to MCO and that of the non-oxidized insulin are presented in the mass range 5,805-5,961 (Fig. 4a, b). Figure 4a shows that the intensity of the mass signal at $5820.62 \mathrm{Da}$ (indicating incorporation of one oxygen atom) and the intensity of the mass signal at $5852.61 \mathrm{Da}$ (indicating incorporation of three oxygen atoms) are much more intense after oxidation. Note that signals indicating incorporation of several other numbers of oxygen atoms were detected too, although with lower intensity. Although MS analysis cannot detail which amino acid is exactly oxidized, our calculation provides a first estimation for the extent of $\mathrm{MCO}$ in the insulin monomer. 
Fig. 3 (a) SEC with intrinsic tyrosine fluorescence detection (Ex 275 nm-Em 302 nm) of insulin oxidized for $3 \mathrm{~h}$ at room temperature in $\mathrm{ABI} 0.25 \mathrm{M}$ (in red) and its control (in blue). (b) MS/MS of peptidic fragment obtained from oxidized insulin in $A B I 0.25 \mathrm{M}$, reduced (DTT), alkylated (IAM), and digested with Glu-C. The amino groups added through Michael addition to the oxidized phenylalanine are highlighted in blue.
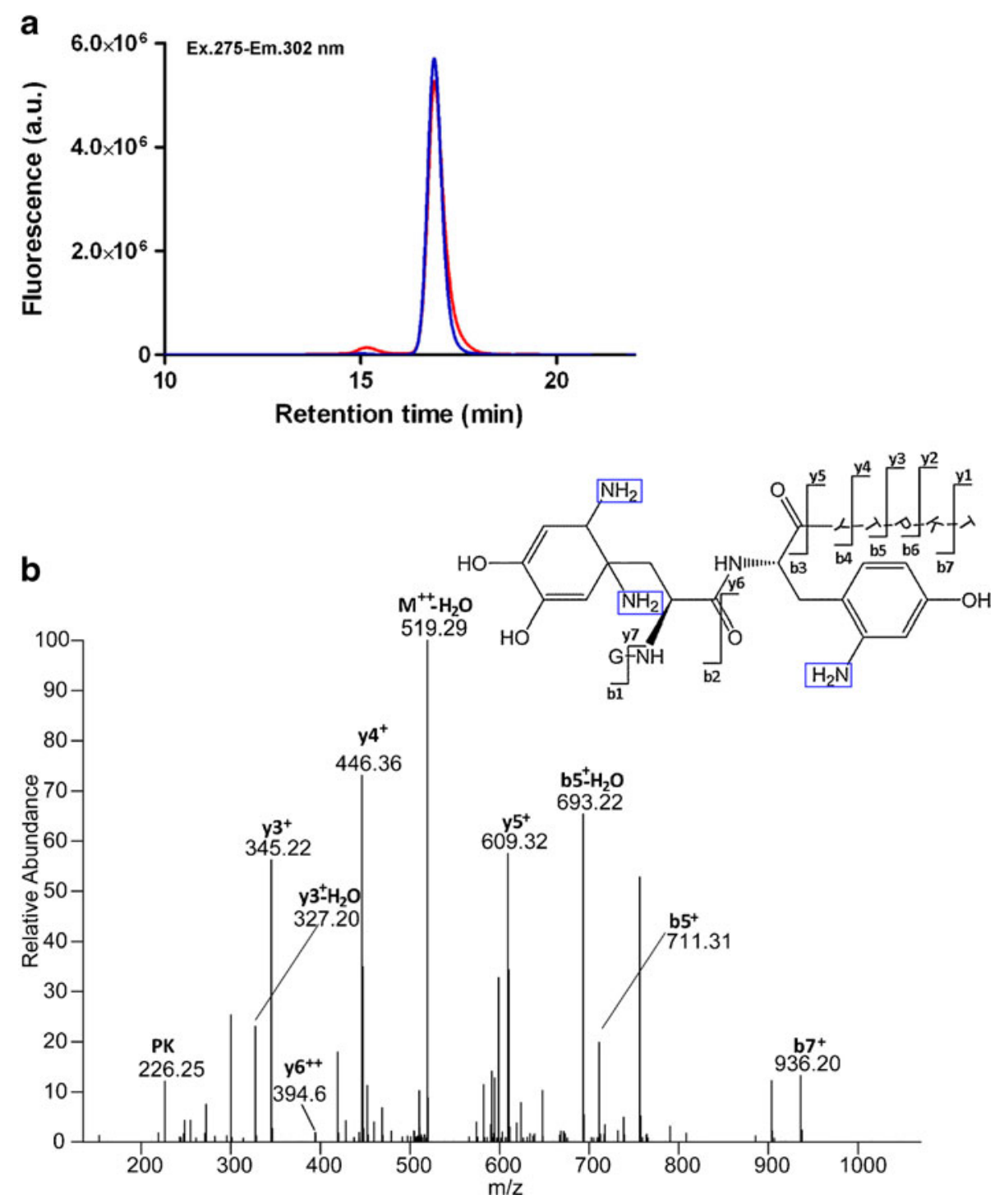

\section{Fragmentation}

In order to detect and quantify the yield of insulin fragments relative to native insulin and to understand if fragmentation, measured by SEC, occurred during sample preparation for analysis (reduction, alkylation, ABS-derivatization and digestion) or prior to sample preparation, i.e. during the exposure of insulin to $\mathrm{Cu}^{2+}$ and L-ascorbate, MS analysis of native and oxidized insulin was performed prior to and after reduction, alkylation, ABS-derivatization and digestion. Figure $4 \mathrm{c}$ and d represent a zoom (16X) into the mass region between 100 and 5805 Da: clearly the oxidized insulin contains new peptides of a lower molecular weight compared to insulin. We processed the MS spectra of oxidized and non-oxidized insulin as follows: 1) deconvolution using the maximum entropy distribution algorithm; 2) sum of the intensities of all the fragments with a molecular weight between that of glycine (the smallest amino acid in insulin) and the molecular weight measured for insulin (i.e. $5804.63 \mathrm{Da})$ minus the molecular weight of glycine, after hydrolysis. The procedure that was employed is summarized in formula 1:

$I_{\text {total }}=\sum_{i=j}^{k}[\text { Fragment }]_{i}\left\{\begin{array}{c}j=\operatorname{Mw}(\text { Gly })=75.03 \\ k=\operatorname{Mw}\left(\text { Insulin }- \text { Gly }+H_{2} O\right) \\ k=5804.63-75.03+18 \\ {[\text { Fragment }] i=\text { Mw of the } i^{\text {th }} \text { fragment }}\end{array}\right.$

The MS spectra of the oxidized and native insulin that were used for this calculation are displayed in Fig. 4c and d, respectively. Figure 5 represents the histograms plotted using the intensity values of the same spectra. The total intensity of the control (i.e. native insulin), was calculated between masses of 0 Da and 


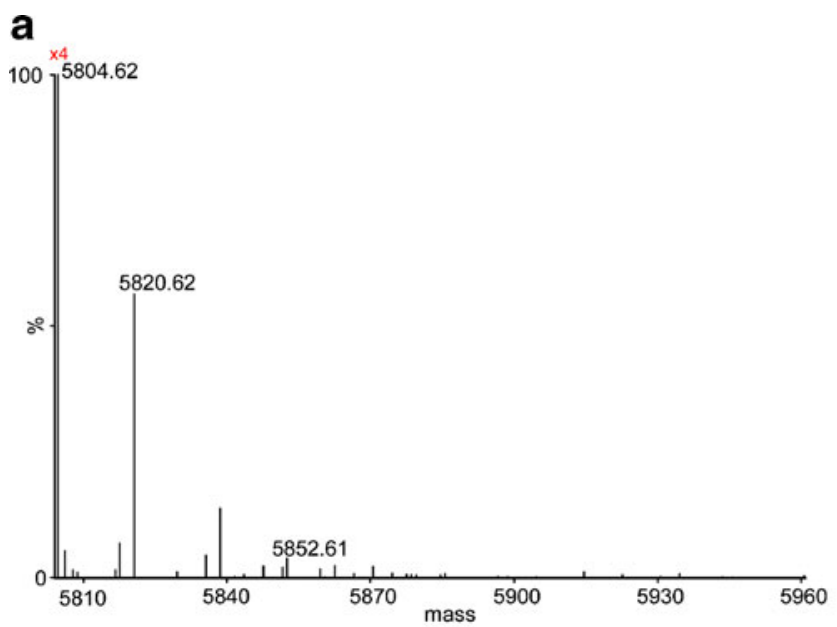

\section{C}

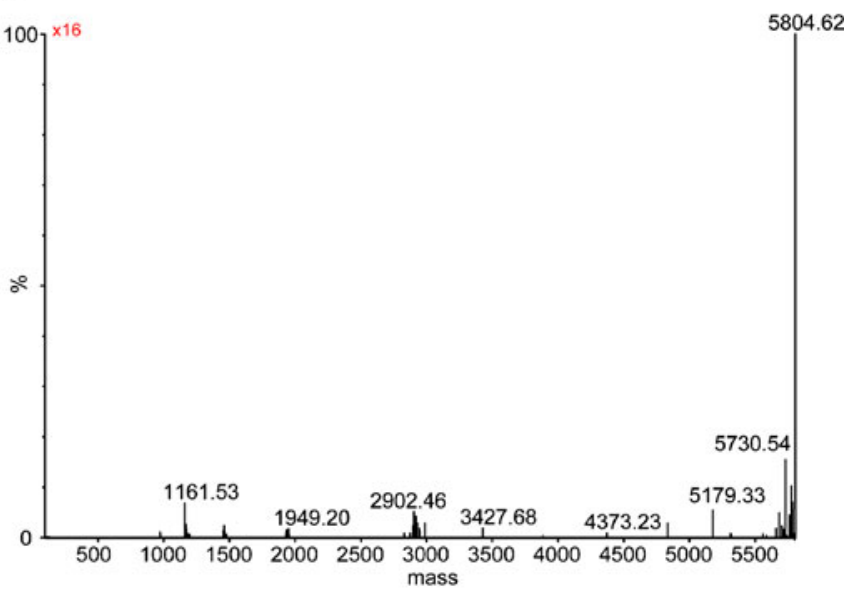

b

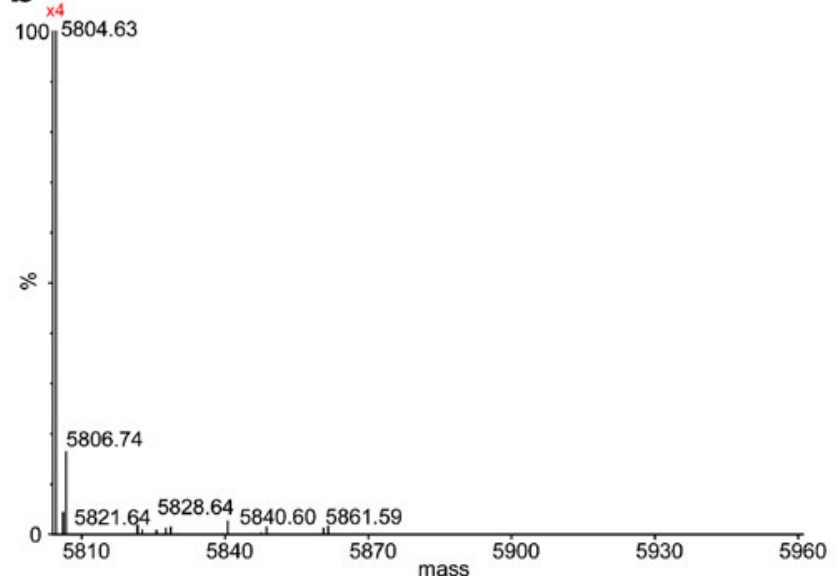

d

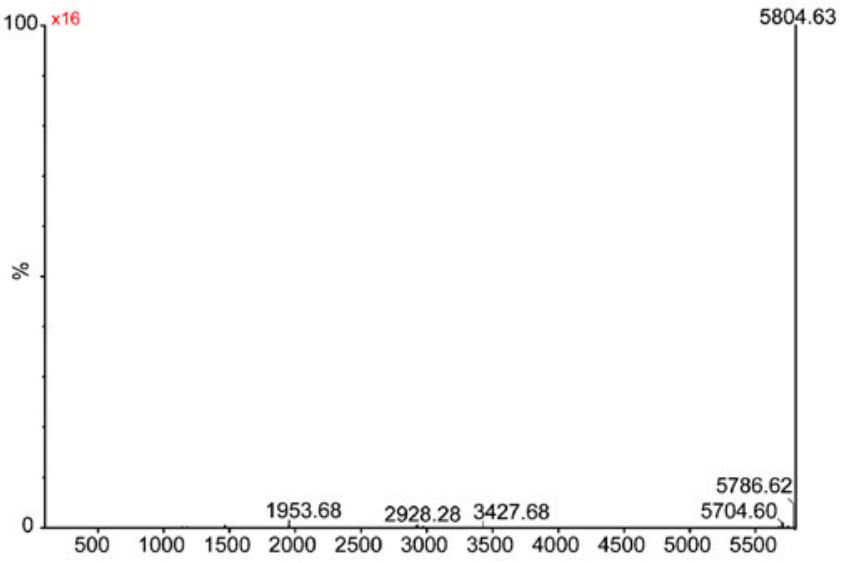

Fig. 4 Mass spectrum (MS) of undigested insulin and undigested insulin oxidized for $3 \mathrm{~h}$ at room temperature in $50 \mathrm{mM} \mathrm{PB}$, $\mathrm{pH} 7.4$. Spectra are shown for oxidized insulin (a, c) and native insulin (b, d) in the mass range 5805-596I to show the oxidized monomer (a, b) and in the mass range 100-5805 to show the fragments (c, d). Spectra were obtained using the maximum entropy distribution algorithm implemented in the Masslynx MaxEnt software (Waters Corporation, Milford, MA) using an adduct of I proton. (Please note that 5804.63 represents the molecular mass of unprotonated insulin.)

36,000 Da, i.e. until just beyond the theoretical molecular weight of the insulin hexamer. Based on this calculation, the total yield of fragments in the non-oxidized control was $0.3 \%$ compared to $3.1 \%$ in insulin exposed to $\mathrm{Cu}^{2+}$ and $\mathrm{L}$-ascorbate (percentages have been calculated dividing the total intensity of the fragments over the total intensity of the native insulin used as a control). For a better view of the fragments, we provide a zoom of the range between $100-5,805 \mathrm{Da}$ of native insulin and oxidized insulin (Fig. 4c, d). Altogether these results suggest that $\mathrm{MCO}$ induces peptidic fragmentation. We did not explore in more detail the mechanism(s) by which such fragmentation occurs, nor did we search for all the possible cross-link in which the new N-termini could be involved. However, we did note the generation of new cross-links between insulin and such fragments (see below), which contain new $\mathrm{N}$-termini and $\mathrm{C}$-terminal amino acids not generated by Glu-C digestion.

\section{Identification of Chemical Modifications by MS/MS Analysis of Reduced, Alkylated, ABS-Derivatized and Digested Samples}

The FT-ICR MS analysis of oxidized and native insulin (control) was performed after reduction, alkylation, ABSderivatization and digestion with Glu-C, by injecting the samples into the mass spectrometer by liquid chromatography. The aim of this analysis was to map the chemical modifications in the primary structure of insulin, to identify the nonreducible cross-links involved in insulin aggregation and to identify the fragments. Because different kind of oxidized, ABS-derivatized, and non-oxidized fragments were found, we hereafter define "fragments" as peptides resulting from at least one cleavage site that differs from the one expected from proteolytic digestion by Glu-C (i.e. after glutamic acid; Glu; E) and we define "Glu-C fragments" as peptides originating from the expected proteolytic cleavage sites of Glu-C. Table II lists all the detected "Glu- 


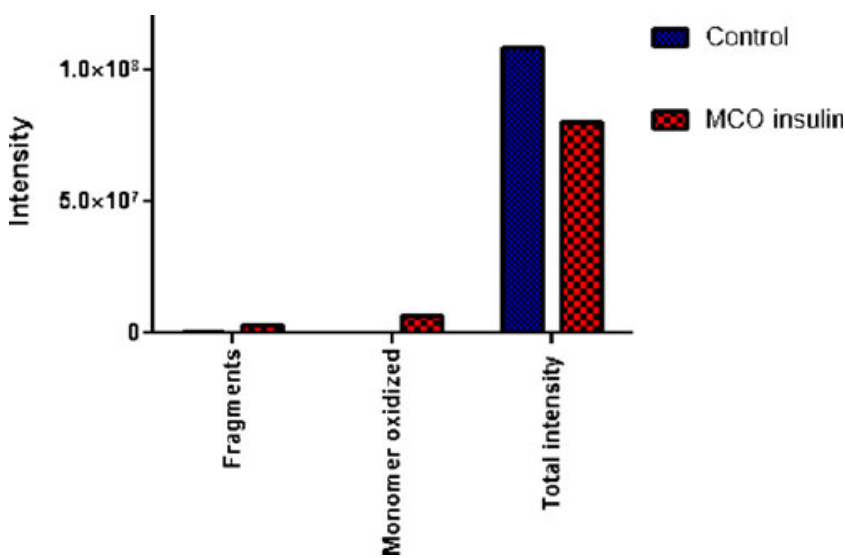

Fig. 5 Plot representing the intensity of fragments and oxidized monomer relative to the total intensity of all detected peaks for native insulin (control, in blue) and insulin oxidized for $3 \mathrm{~h}$ at room temperature in $50 \mathrm{mM} \mathrm{PB}, \mathrm{pH} 7.4$ (in red). Data are derived from the spectra reported in Fig. 4.

C fragments" (oxidized and ABS-derivatized) and "fragments" (oxidized, ABS-derivatized and non-oxidized). Non-oxidized Glu-C fragments were measured for both oxidized and native insulin but are not listed in Table II, since their presence was expected and represents the majority of Glu-C fragments. MS/ MS spectra of non-oxidized fragments (available in the supplementary material) are only briefly discussed in this manuscript, because the main focus of our work was to elucidate the chemical mechanisms of insulin aggregation during MCO. As displayed in Table II, the following section is divided into the following subsections: Oxidized Glu-C Fragments, ABSDerivatized Glu-C Fragments, Oxidized Fragments, ABSDerivatized Fragments, Non-oxidized Fragments. Regarding the description of these fragments, the prefixes and subscripts A and $\mathrm{B}$ refer to sequences from the A and B chain, respectively, while $\mathrm{b}$ and $\mathrm{y}$ refer to the cleavage sites according to the nomenclature introduced by Roepstorff (34).

\section{Oxidized Glu-C Fragments}

$R_{\mathrm{B} 22} \mathrm{GFF}^{*} \boldsymbol{Y}^{*} T P K T_{\mathrm{B} 30}$. The $\mathrm{C}$-terminal region of chain $\mathrm{B}$ contains two Phe and one Tyr in positions B24, B25 and B26, respectively. DOPA and DOCH can arise from the oxidation of all these residues. Thus it becomes of primary importance to identify the ions, which allows us to discriminate between different oxidation products. The MS/MS spectra reported in supplementary Fig. S1A provides evidence for the oxidation of Phe B25 to Tyr where * indicates the incorporation of one oxygen atom. The ion $\mathrm{b} 3^{+}$, despite its low intensity, indicates that Phe B24 is present in the native, non-oxidized state, where $\mathrm{m} / \mathrm{z} 361.2$ corresponds to the singly charged ion of the sequence RGF. Instead, the ion $\mathrm{b} 4^{+}$provides evidence for oxidation of Phe B25. A careful analysis of the spectra (Figures $\mathrm{S} 1 \mathrm{~B})$ reveals the contemporary presence of two different $\mathrm{y} 5^{+}$ ions, indicated as (F4) $5^{+}$with $\mathrm{m} / \mathrm{z} 625.5$ (which corresponds to a structure containing Tyr B26 oxidized) and, $(H O-F 4) y^{+}$ with $\mathrm{m} / \mathrm{z} 609.4$ (which corresponds to a structure containing Phe B25 oxidized). Panel $\mathrm{C}$ shows the $\mathrm{b} 4^{+}$ions for these two coexisting structures, again representing oxidation of Phe B25 or Tyr B26, respectively. Hence, both Phe B25 and Tyr B26 are targets for the incorporation of one oxygen atom.

$A_{B / 4} L Y^{*} L V C G E_{B 2 / .}$ Supplementary Figure $S 2$ displays the MS/MS data for the peptide ALY*LVCGE, which contains an expected Glu-C cleavage site, where $\mathrm{Y}^{*}$ represents the incorporation of one oxygen into Tyr, i.e. the formation of DOPA (the Cys residue is alkylated with IAM). This product is confirmed through the presence of the ions $\mathrm{b} 3^{+}-\mathrm{b} 5^{+}$ (although $\mathrm{b}^{+}$and $\mathrm{b} 4^{+}$show low intensities) and $\mathrm{y} 5^{+}$. The singly charged ions $\mathrm{b} 3^{+}, \mathrm{b} 4^{+}$and $\mathrm{b} 5^{+}$indicate that the oxygen is in one of the following sequences: ALY, ALYL, or ALYLV. The singly charged ion $\mathrm{y}^{+}$indicates that the sequence LVCGE is not oxidized. Therefore, oxygen incorporation must have occurred on one of the first three amino acids, ALY, where Tyr represents the most oxidation-sensitive target amino acid. Further evidence for Tyr B16 oxidation through ABS derivatization is given below.

$F^{*}{ }_{B /} V N Q H L C G S H L V E_{B / 3}$. The N-terminus of chain B, Phe B1, displays a mass increase consistent with the oxidation of Phe B1 to cyclohexadienone. The MS/MS analysis (Figure S3) of the sequence F*VNQHLCGSHLVE indicates the formal addition of one oxygen atom and loss of 2 hydrogens from Phe B1, i.e. a mass increase of $14 \mathrm{Da}$ through the appearance of the following ions: $\mathrm{y}^{+}$, which suggests that the sequence HLCGSHLVE is not oxidized, and $\mathrm{b}^{+}$, indicating the oxidation of the sequence FVNQHL. In this sequence, HL can be excluded as an oxidation target because of the nature of $\mathrm{y}^{+}$. Since in the sequence FVNQ $\mathrm{F}$ is most sensitive to oxidation we conclude that oxidation targets Phe $\mathrm{B} 1$.

$F^{* *}{ }_{B}$ VNQHLCGSHLVEALYLVCGE $E_{B 2 I}$. Phe B1 can be further oxidized to DOCH (Figure S4). The observed masses of the ions $\mathrm{y} 17^{++}-\mathrm{H}_{2} \mathrm{O}$ and $\mathrm{y} 17^{+}$exclude any oxidation of other amino acids sensitive to oxidation in $\mathrm{F}^{* *}{ }_{\mathrm{B} 1}$ VNQHLGGSHLVEALYLVGGE $\mathrm{B} 21_{1}$. The ion $\mathrm{y}^{+}$ with $\mathrm{m} / \mathrm{z} 1899.82$ shows an intensity which is about $80 \%$ of that of $\mathrm{bl6}^{+}$with $\mathrm{m} / \mathrm{z} 1898.75$; thus, it should not be considered the first isotope peak of $\mathrm{b}^{+} 6^{+}$, which would be expected at $\mathrm{m} / \mathrm{z} 1899.75$.

\section{ABS-Derivatized Glu-C Fragments}

$R_{\mathrm{B} 22}$ GFFY $^{\#}$ TPKT $_{\mathrm{B} 30}$ and $R_{\mathrm{B} 22}$ GFFY\#\# $T P K T_{\mathrm{B} 30}$. Supplementary Figure S5 shows that Tyr B26 is converted to DOPA and/or DOCH, indicated by derivatization with one molecule of ABS (indicated with the symbol ${ }^{\#}$ ). The ions with $\mathrm{m} / \mathrm{z}$ 


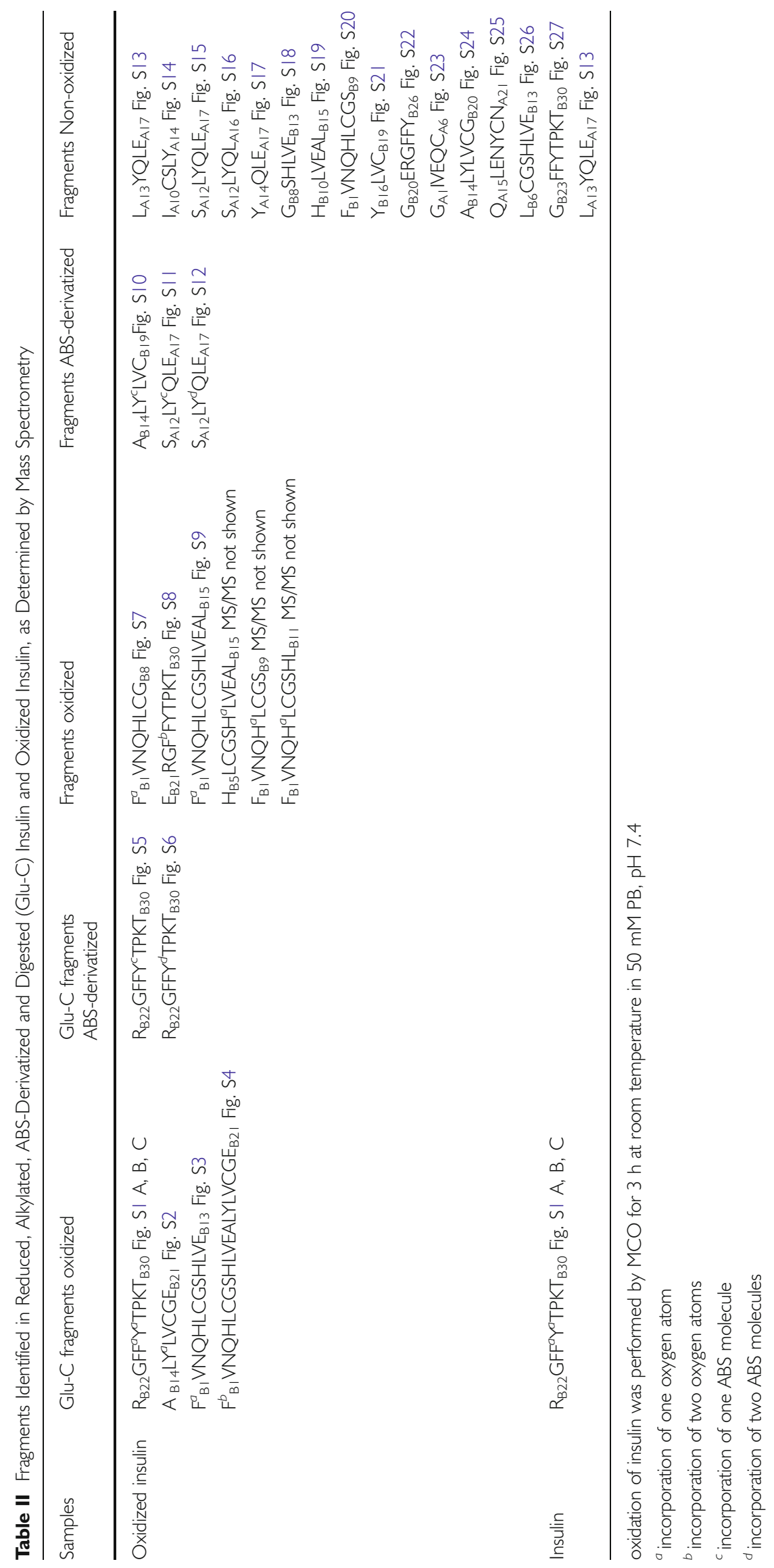


361.28 and $\mathrm{m} / \mathrm{z} 508.26$, corresponding to $\mathrm{b}^{+}$and $\mathrm{b} 4^{+}$, respectively, suggest that both Phe B24 and Phe B25 are not oxidized in this sequence. If for instance, Phe B24 (in the sequence $\mathrm{RGF}_{\mathrm{B} 24} \mathrm{FYTPKT}$ ) had been oxidized, the $\mathrm{b}^{+}$ion would have been expected with $\mathrm{m} / \mathrm{z} 377.28$ (i.e. $361.28+$ $16 \mathrm{Da}$. Instead, the ions $\mathrm{b}^{+}{ }^{+}$and $\mathrm{b} 6^{+}$provide evidence that Tyr B26 is the target of oxidation. For additional evidence, supplementary Figure S6 displays the MS/MS spectrum of $\mathrm{RGFFY}^{\# \#}$ TPKT, derivatized with two molecules of ABS, as shown in the displayed structure. Here, the ions $\mathrm{b}^{+}$and $\mathrm{b} 4^{+}$ are identical to the ones reported in Figure S5, although more intense. The ion with $\mathrm{m} / \mathrm{z} 1037.29$ corresponding to the ions $\mathrm{b}^{+}{ }^{+}$and $\mathrm{y} 5^{+}$reported in the inset of Figure S6, confirm that the original Tyr contains two ABS molecules. We had realized in the past $(19,20)$, that derivatization with ABS can lead to the incorporation of one or two molecules of ABS into the final benzoxazole product (see scheme 1), depending on the availability of ammonia, resulting in competition of ammonia and ABS for the 6-position in benzoxazole. In addition to that, it seems that the competition between ammonia and ABS depends on the steric hindrance of the peptide which is derivatized: i.e., derivatization with two ABS molecules of sterically less accessible DOPA and DOCH can be kinetically less favorable than that of more exposed residues. It must be noticed that the sequence $\mathrm{R}_{\mathrm{B} 22}$ GFFYTPKT $_{\mathrm{B} 30}$, depicted in Figures $\mathrm{S} 5$ and $\mathrm{S} 6$, does not necessarily belong to the same B chain: in other words, the sequence derivatized with one ABS molecule could be involved in the formation of HMWO, while the doubly ABS-derivatized sequence can actually be present in the monomer as well, although oxidized, and subsequently be derivatized with two ABS molecules.

\section{Oxidized Fragments}

$F^{*}{ }_{B}$ VNQHLCG $G_{B 8}$. Phe B1 is oxidized to hydroxylated Phe, indicated through the MS/MS data displayed in Figure S7: the ion $\mathrm{y}^{+}$shows that none of the amino acids in the sequence $\mathrm{C}$-terminal to Phe B1, VNQHLCG, is oxidized. Therefore, the ion $\mathrm{b} 5^{+}$confirms oxidation of Phe B1. In fact, Phe hydroxylation can occur in positions ortho, meta and para; however, only the latter would lead to Tyr.

$E_{B 2 I} R G F^{* *} F Y T P K T_{B 30}$. The MS/MS data displayed in Figure S8 are consistent with the oxidation of Phe B24 to DOCH. The ions $\mathrm{b} 4^{+}$and $\mathrm{y} 6^{+}$are fundamental to confirm the oxidation of Phe B24 since the first indicates the presence of the sequence ERGF**, and the second, suggests that the sequence FYTPKT is not oxidized. Further confirmation of the chemical structure in which Phe B24 is doubly oxidized arises from the detection of the internal fragment GF**FY with $\mathrm{m} / \mathrm{z} 545.39$, which can be produced during the analysis via specific pathways consistent with the mobile proton model (35).

$F^{*}{ }_{B}$ VNQHLCGSHLVEAL $L_{B / 5}$. Phe B1 oxidation is also evident in the sequence $\mathrm{F}^{*} \mathrm{VNQHLCGSHLVEAL}$, indicated by the MS/MS data displayed in Figure S9. Here it is sufficient to consider the ions $\mathrm{y} 13^{+}$and $\mathrm{b} 14^{++}$. The ion $\mathrm{y} 13^{+}$ indicates that the sequence NQHLCGS is not modified. On the other hand $\mathrm{bl} 4^{++}$indicates oxidation in the sequence FVNQHLCGSHLVEA. By exclusion, this limits oxidation to the N-terminal subsequence FV, where F represents the most oxidation-sensitive amino acid.

\section{ABS-Derivatized Fragments}

$A_{B / 4} L Y^{\#} L V C_{B / 9}$. We further corroborated the formation of DOPA through derivatization of the oxidized peptide ALY*LVG with ABS (Figure S10). The only possible site for derivatization in this peptide is an oxidized Tyr residue, since ABS derivatization requires the presence of DOPA (which during the derivatization is oxidized with $\mathrm{K}_{3} \mathrm{Fe}(\mathrm{CN})_{6}$ to $\mathrm{DOCH})$.

$S_{A / 2} L Y^{\#} Q L E_{A / 7}$ and $S_{A / 2} L Y^{\# \#} Q L E_{A / 7}$. The MS spectra presented in Figures $\mathrm{S} 11$ and $\mathrm{S} 12$ provide evidence for the ABS derivatization of Tyr A14 within the sequence SLYQLE. Successful derivatization with one and two molecules of ABS indicates oxidation of Tyr A14 to either DOPA or DOCH. In both figures the ions $\mathrm{b}^{+}$ with $\mathrm{m} / \mathrm{z} 560.11$ and 730.07 , respectively and, the ion $\mathrm{y}^{+}$with $\mathrm{m} / \mathrm{z} 748.39$ and 918.15 , respectively, indicate derivatization of the original $\mathrm{Tyr}$ residue with one and two molecules of ABS.

\section{Non-oxidized Fragments}

Two types of non-oxidized fragments were detected in the control (Table II). They are likely generated during production or storage as a consequence of low traces of transition metals. Instead, 14 non-oxidized fragments were detected as a result of MCO, summarized in the last column of Table II. The MS/ MS data of all these fragments are reported in the Supplementary Material (Figures S13-S27).

\section{Covalent Cross-Links}

This section focuses on the identification of covalent crosslinks by MS/MS analysis. Figure 6 summarizes all the covalent cross-links detected as a result of the MCO of insulin.

Gly AI -Tyr Al4 Cross-Link. Figure 7a displays the MS/MS data consistent with a cross-link between Gly Al and Tyr A14. 
The ions $\mathrm{Bbl}^{+}, \mathrm{By}^{+}$and $\mathrm{Ab} 3^{+}$are the most relevant ones to confirm the cross-link between Gly Al and Tyr A14. In particular $\mathrm{Bbl}^{+}$shows that the sequence ICSLY is covalently attached to Gly. The ion $\mathrm{By}^{+}{ }^{+}$indicates that the sequence IVE is not involved in the cross-link and, therefore, can be dissociated during the MS/MS analysis since it is connected to Gly Al only through a peptide bond (36). Finally, the ion $\mathrm{Ab}^{+}$provides evidence that ICS is not involved in the crosslink. In the structure provided in Fig. 7a, the covalent attachment of Gly A1 to Tyr A14 is representatively shown for the 6 position of the original DOPA (or DOCH) product. While, in principle, Michael addition is possible also at positions 1 and 2 , position 6 is sterically less hindered, and that is why we selected to represent the adduct formation at position 6 . However, we have currently no evidence for this regioselectivity. Further confirmation of the structure reported in Fig. 7a was obtained through the spectrum displayed in Fig. 7b, where the ion $\mathrm{M}^{+}-\mathrm{H}_{2} \mathrm{O}$ was detected.

Gly A I-Tyr B 26 Cross-Link. Figure 7c represents the crosslink of Gly A1 of the sequence GIVE to Tyr B26. The mass spectra displayed in Fig. 7c represents sodium adducts of the respective peptide fragment(s), likely due to incomplete removal of buffer during dialysis. Therefore, all the $\mathrm{m} / \mathrm{z}$ of the ions presented in Fig. 7c have an increased mass of $23 \mathrm{Da}$. The ion $[\mathrm{By} 2+\mathrm{Na}]^{+}$, representing the singly charged sequence
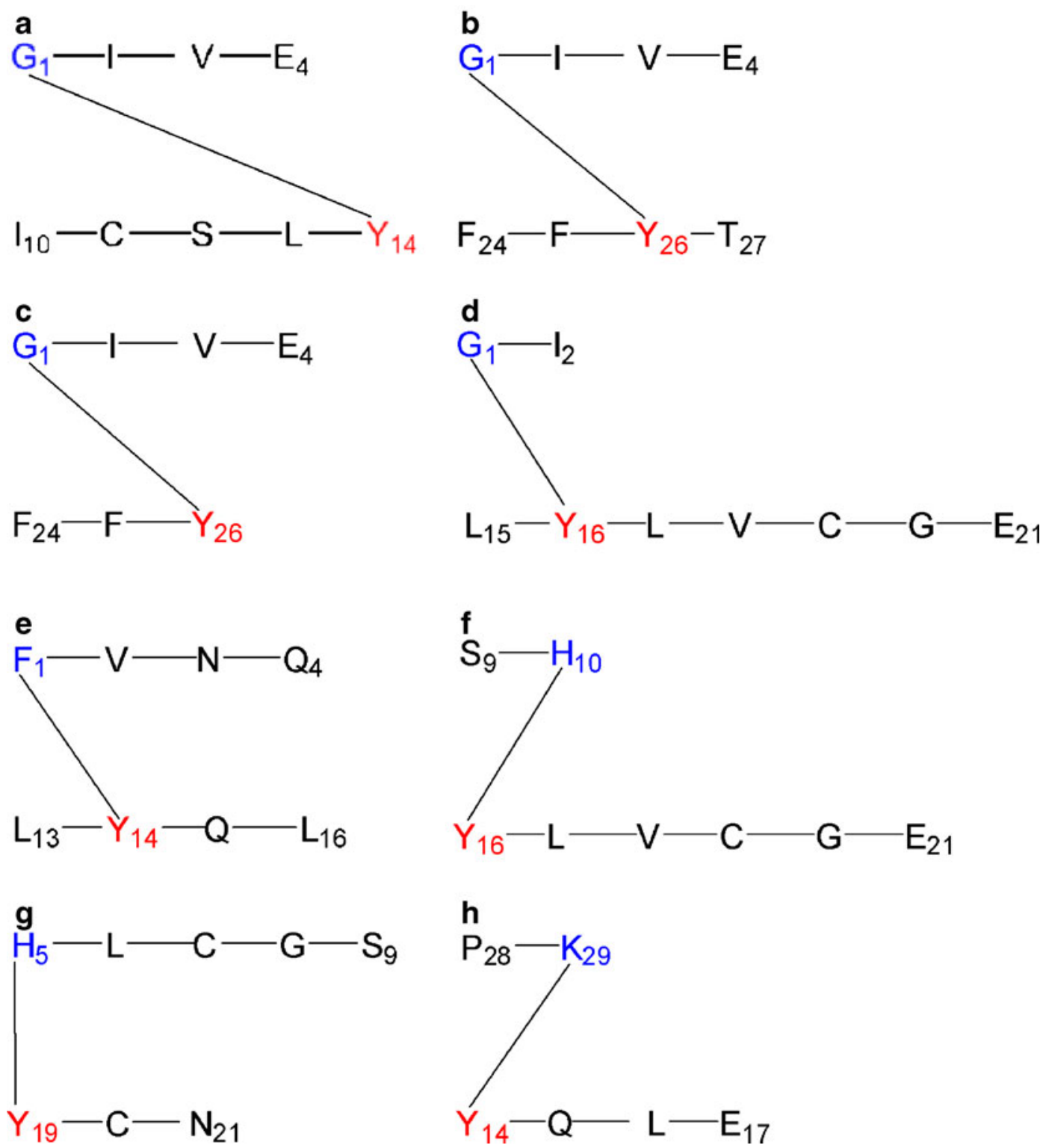

Fig. 6 Identified inter-/intra-molecular cross-links measured after MCO of insulin, between (a) Gly AI-Tyr AI4, (b, c) Gly AI-Tyr B26, (d) Gly A I-Tyr BI6, (e) Phe BI-Tyr AI 4, (f) His B I0-Tyr BI6, (g) His B5-Tyr A I9, (h) Lys B29-Tyr AI 4. In blue are shown the amino acids with nucleophilic properties and in red the amino acids oxidized to $\mathrm{DOCH}$, which are Michael acceptor for nucleophilic addition. Further details are given in Fig. 7 and in the main text in the section "Covalent Cross-Links". 
VE, suggests that the amino acids $\mathrm{Val}$ and Glu are not involved in the new covalent bond. If this sequence had been involved in the new covalent bond with Tyr, it would not have been possible to detect the ion $[\mathrm{By} 2+\mathrm{Na}]^{+}$, since only dissociation of peptide bonds occurs during the low energy collision with the inert gas. $[\mathrm{Bb} 2+\mathrm{Na}]^{+}$indicates that the sequence GI is covalently bound to the sequence FFY. We excluded the possibility of DOPA as the product of one of the Phe residues, since in such case the ion $[\mathrm{Bb} 2+\mathrm{Na}]^{+}$would have a mass increase (relative to the expected mass of the fragment of unmodified insulin) larger than $16 \mathrm{Da}$ (the oxidation of Phe to DOPA and DOCH requires two oxygen atoms); if one of the Phe residues were exclusively oxidized to Tyr, the ion $[\mathrm{Bb} 2+$ $\mathrm{Na}]^{+}$would have the same molecular weight as the one detected in this MS/MS spectrum. In such case, however, it would not be possible to observe Michael addition, since the new Tyr residue (generated from the mono-oxidation of Phe) is not a Michael acceptor unless it is further oxidized to quinone.
In Fig. $7 \mathrm{~d}$ the original sequence FFY shows additional oxidation of both Phe residues (in contrast to Fig. 7c, which shows the native Phe residues in FFY): one of them to DOPA and the second one to a 6 -amino substituted DOPA, likely originating from Michael addition of ammonia to a DOPA oxidation product. The ions $\mathrm{By}^{+}$, with $\mathrm{m} / \mathrm{z} 612.22$, displayed in the inset, and $\mathrm{Abl}^{+}$, with $\mathrm{m} / \mathrm{z}$ 626.29, unequivocally indicate that the covalent bond is between Gly and Tyr: By ${ }^{+}$represents the singly charged sequence Y-GIVE and $\mathrm{Abl}^{+}$corresponds to the singly charged sequence FFYG. The combination of both demonstrates that the new covalent bond, not dissociable during MS/MS analysis, is located between Tyr and Gly. Importantly, our results show that predominantly Tyr oxidation products serve as Michael acceptors for cross-link formation during the MCO of insulin (see also below). There are several possible rationales for this behavior, including protein conformation and the respective yields of Tyr and Phe oxidation products: the
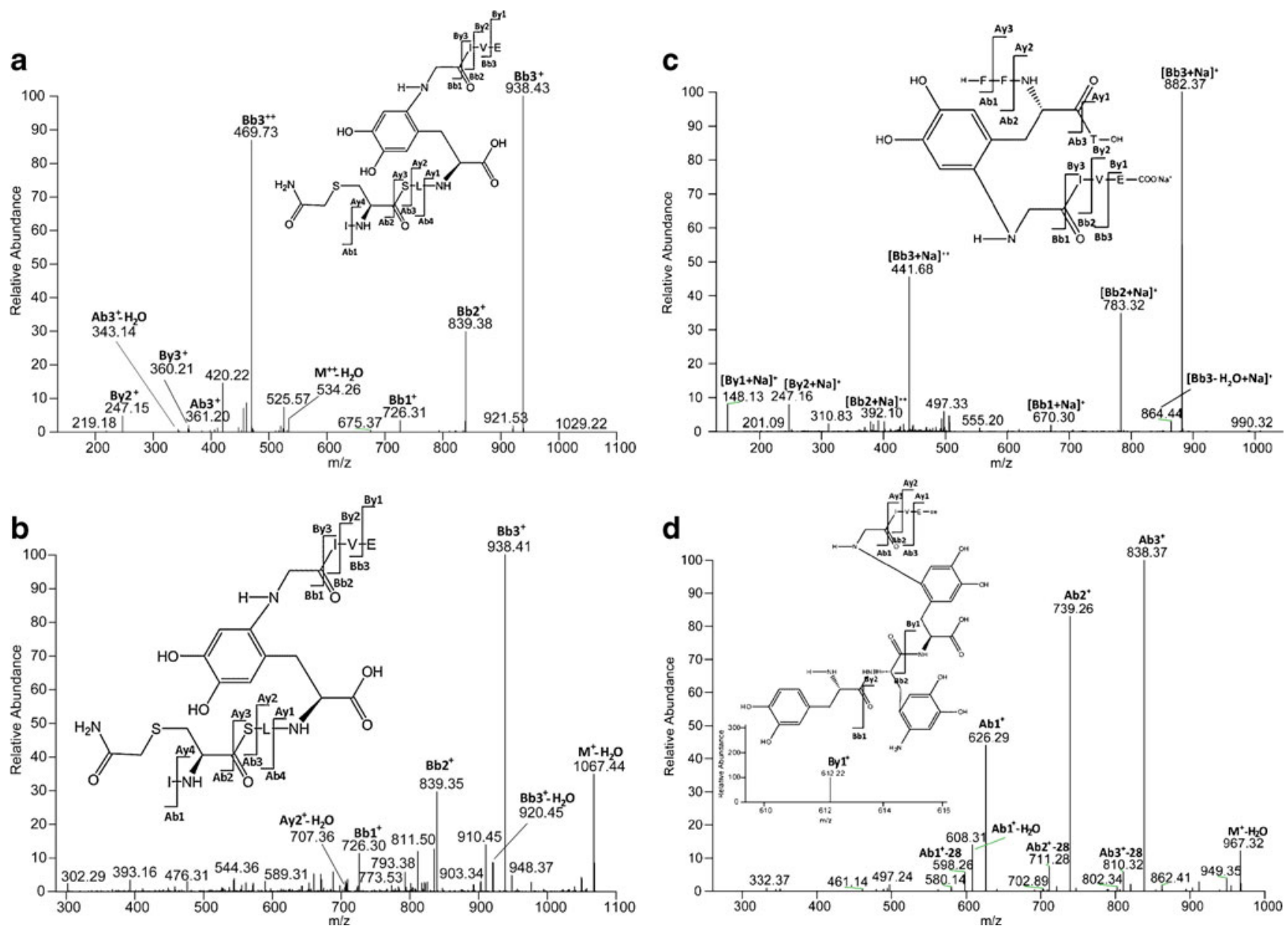

Fig. $7 \mathrm{MS} / \mathrm{MS}$ of $(\mathbf{a}, \mathbf{b})$ sequence GIVE cross-linked through the glycine AI to the sequence ICSLY, (c) sequence GIVE cross-linked through the glycine AI to the sequence FFYT, (d) sequence GIVE cross-linked through the glycine AI to the sequence FFY, (e) sequence GI cross-linked through the glycine AI to the sequence LYLVCGE, (f) sequence FVNQ cross-linked through the phenylalanine BI to the sequence LYQL, (g) sequence SH cross-linked through the histidine BIO to the sequence YLVCG, (h) sequence HLCGS cross-linked through the histidine B5 to the sequence YCN, (i) sequence PK cross-linked through the lysine B29 to the sequence YQLE. The fragments have been obtained after reduction (DTT), alkylation (IAM), ABS-derivatization and digestion (Glu-C) of oxidized insulin. Further explanation can be found in the text. 

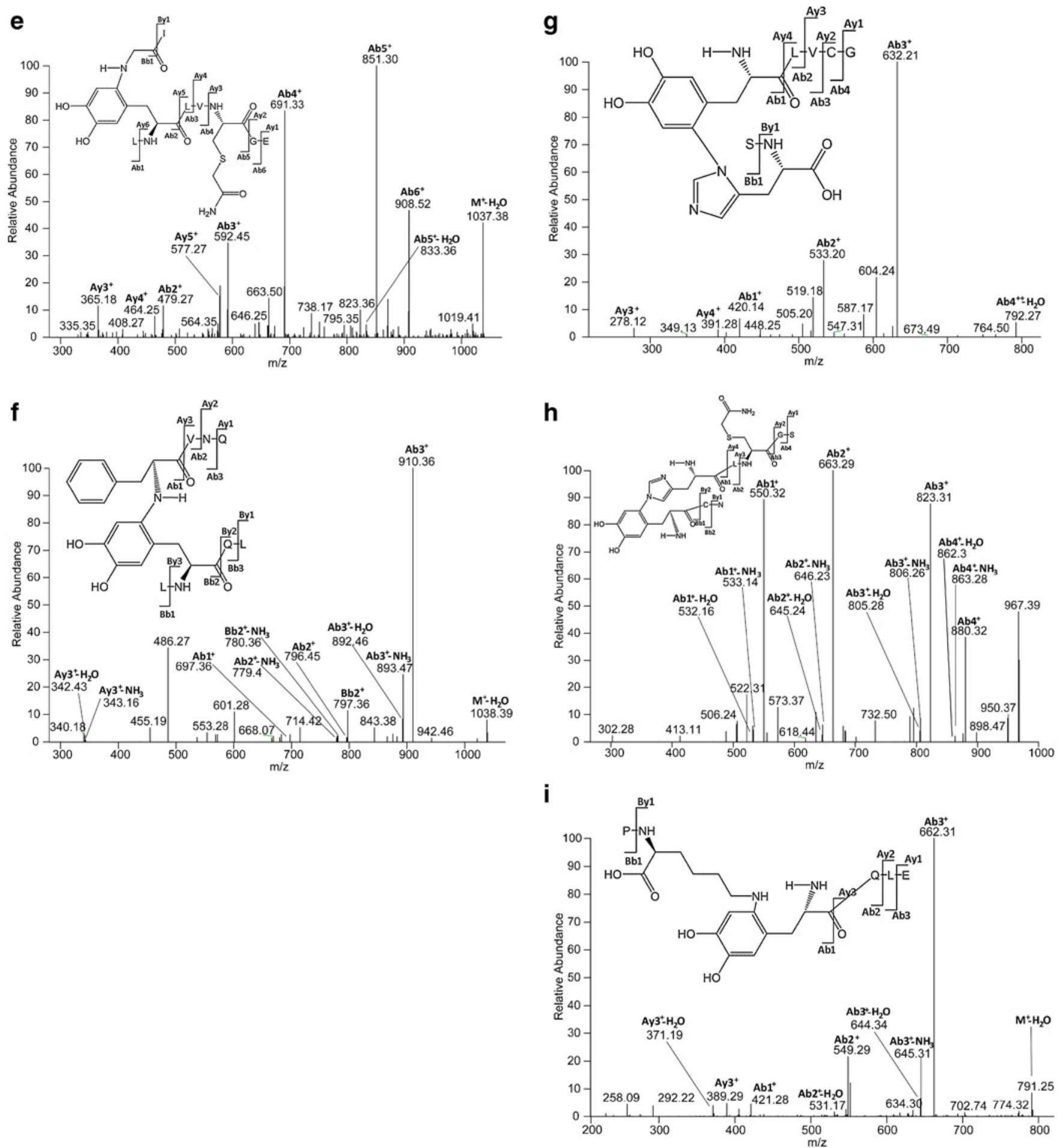

Fig. 7 (continued).

oxidation of Phe to DOCH requires one additional oxidation step compared with that of Tyr to DOCH, suggesting that DOCH formation from Tyr is kinetically favorable.
Gly A I - Tyr B I6 Cross-Link. Figure 7e displays MS/MS data consistent with a covalent cross-link between Gly Al and Tyr B16. The most relevant ion in this figure is $\mathrm{Ab}^{+}$with $\mathrm{m} / \mathrm{z}$ 479.27, which demonstrates that the sequence GI is 
covalently bound to LY. Since Ile and Leu do not contain functional groups amenable to Michael addition, we conclude that the covalent bond is formed between Gly and Tyr.

Phe BI-Tyr Al4 Cross-Link. Phe B1 is not only a possible target for oxidation; the free N-terminal amino group can react via Michael addition with DOCH. The spectrum depicted in Fig. 7f shows the relevant ions consistent with a cross-link between Phe Bl and Tyr A14: $\mathrm{Abl}^{+}$with $\mathrm{m} / \mathrm{z}$ 697.36 shows the existence of a peptide containing the following amino acids: Phe, Tyr, Gln and two Leu, plus the molecular weight of one oxygen atom. However considering only the ion $\mathrm{Abl}^{+}$, it is not possible to localize the oxygen addition and to characterize the nature of the crosslink. The ion $\mathrm{Bb} 2^{+}$, with $\mathrm{m} / \mathrm{z}$ 797.36, indicates that the sequence FVNQ is connected to the sequence LY. The ion $\mathrm{Ay}^{+}{ }^{+}-\mathrm{NH}_{3}$, with $\mathrm{m} / \mathrm{z} 343.16$, excludes any covalent cross-link of the sequence VNQ. In the sequence LY only Tyr oxidation can lead to a Michael acceptor for the amino terminal of Phe B1, which suggests a cross-link such as depicted in Fig. $7 f$.

His B I0-Tyr B I6 Cross-Link. Figure $7 \mathrm{~g}$ displays a cross-link between His B10 of the sequence $\mathrm{SH}$ and Tyr B16 of the sequence YLVGG. The relevant ions in this spectrum are $\mathrm{Abl}^{+}$and $\mathrm{Ay}^{+}$. Ion $\mathrm{Abl}^{+}$, with $\mathrm{m} / \mathrm{z} 420.14$, suggests that the sequence $\mathrm{SH}$ is covalently bound to the original $\mathrm{Tyr}$ residue (after oxidation of $\mathrm{Tyr}$ to $\mathrm{DOCH}$ ). The deprotonated imidazole nitrogen of His is an appropriate nucleophile for Michael addition, demonstrated for example for His addition to dehydroalanine (36).

His B5-Tyr Al9 Cross-Link. Figure 7h displays a cross-link between His B5 of the sequence HLCGS and Tyr B16 of the sequence YCN and the MS/MS data supporting this assignment. We note that the ion $\mathrm{Abl}^{+}-\mathrm{NH}_{3}$ shows an intensity which is about $80 \%$ of that of $\mathrm{Abl}-\mathrm{H}_{2} \mathrm{O}$. Thus, the ion with $\mathrm{m} / \mathrm{z} 533.14$ should not be considered the second isotope of $\mathrm{Abl}^{+}-\mathrm{H}_{2} \mathrm{O}$, suggesting that the N-terminal amino group of the His is free and not involved in the new covalent bond.

Lys B29-Tyr Al 4 Cross-Link. Figure 7i represents the crosslink between Lys B29 and Tyr A14. The relevant ion in the spectra is $\mathrm{Abl}^{+}$, since it localizes the cross-link to Tyr and the amino acids Pro and Lys in the sequence PK. Because the MS/MS data in Fig. 7i shows no $\mathrm{B}$ ions, we cannot conclude whether the cross-link involves the side chain amino group of Lys or the amino group of Pro. The latter would require that non-oxidative fragmentation between Thr B27 and Pro B28 occurs prior to cross-linking; the side chain amino group of Lys B29 represents a good nucleophile and it can therefore be assumed that at least some of the cross-links are formed through the reaction of Tyr A14 with Lys B29.

\section{DISCUSSION}

We performed a detailed mass spectrometric analysis of insulin in order to elucidate the mechanisms and amino acid residues involved in $\mathrm{MCO}$ and $\mathrm{MCO}$-mediated aggregation. The oxidation of Phe and Tyr leads to the formation of catechol structures that can be further oxidized to DOCH. These oxidation products serve as Michael acceptors for crosslinks with several nucleophiles present in the insulin sequence. Formation of dityrosine, as a potential structure involved in the cross-linking of insulin, was not detected, neither with fluorescence measurement (see material and methods), nor with the help of MassMatrix software. This is not surprising since it has been reported that only the hydrogen peroxide/ copper system is capable of inducing dityrosine formation (37). Schiff base formation could potentially be in competition with Michael addition, nonetheless such cross-links can be reversed relatively easily and based on our results does not appear to be the main mechanism of insulin aggregation. Changes in the primary structure, as reported in this paper, may alter the biological activity of insulin with severe consequences on the glycemic control. Furthermore, changes in the secondary, tertiary and quaternary structure as a consequence of oxidation, as reported by us before (13), may generate new repetitive epitopes or open the access to hidden epitopes that could contribute to the formation of immunogenic products.

In addition to the characterization and localization of oxidation products, we provided quantitative data on the amount of fragments and oxidized monomers. An important feature of insulin exposed to $\mathrm{MCO}$ is the appearance of fragments, which increases the number of polypeptide nucleophiles available for Michael addition. At this point, we do not know whether the observed insulin fragmentation precedes or follows cross-link formation. Furthermore, it is unknown whether Glu-C might have a different specificity towards oxidized protein. The actual mechanism of cleavage is currently unknown, but we can exclude the classical oxidative cleavage (38) since we did not detect the $\alpha, \beta$-dicarbonyl products expected for such a mechanism. Instead, all nonspecific cleavages appear to involve a hydrolytic cleavage of the respective peptide bonds. It may be possible that the addition of $\mathrm{Cu}^{2+}$ and L-ascorbate promote the formation of peptide-metal complexes with hydrolytic activity, such as described for the cleavage of amides through $\mathrm{Cu}^{2+}$ (39). Surprisingly, most of the non-specific peptide fragments we detected were already reported by other authors, e.g. after the oxidation of glycated insulin by Fenton chemistry $(9,33)$; however, Guedes et al.(33) interpreted the cleavage mechanism as 
oxidative cleavage, which is inconsistent with the intact $\mathrm{C}$ - and $\mathrm{N}$-termini of the detected peptide fragments.

Through MCO experiments at various $\mathrm{pH}$, and in the presence of ammonia, we are able to confirm that Michael addition between insulin chains causes covalent aggregation. In the presence of ammonia, which competes for Michael addition to DOCH, aggregation was almost completely inhibited. Although such experimental conditions allow to prevent aggregation, we noted that the introduction of an amino group on oxidized Tyr or Phe might still have consequences for the immunogenicity of this small polypeptide hormone.

Several proteins have been shown to form aggregates after exposure to $\mathrm{Cu}^{2+} / \mathrm{L}$-ascorbic acid, such as recombinant $\mathrm{SHa}$ (29-231) prion protein (40), superoxide dismutase (41), monoclonal IgG2 (42), interferon alpha 2a $(5,6)$ and interferon beta la (7). The results presented in this paper may serve as a model to rationalize the chemical mechanisms of aggregation during MCO of proteins in general. Although insulin lacks Trp and Met, which are also prone to oxidation $(43,44)$ and are present in most other proteins, DOPA and DOCH should not be formed from oxidation of Trp or Met, thus they cannot act as electron acceptor for Michael addition. Since MCO was performed at $\mathrm{pH}$ 7.4, where insulin is present mainly in the hexameric state (45), the cross-links we measured are likely to be intermolecular cross-links, i.e. formed between different insulin molecules. As an example we calculated the distance of Gly A1 and Tyr A14 and Gly A1 and Tyr A19 within the same A-chain (using Swiss pdb viewer $(46,47)$ and T6 human insulin at $1.0 \AA$ resolution, $1 \mathrm{MSO}$ pdb file). An average of $18.5 \AA$ was measured for a theoretical covalent bond between the amino group of Gly Al and the carbon in ortho of the aromatic ring of $\mathrm{Tyr} \mathrm{A} 14$, and an average of $8.3 \AA$ for the amino group of Gly $\mathrm{Al}$ and the carbon in ortho of the aromatic ring of Tyr A19, which seems to be too far for an intramolecular reaction (e.g., the length of the peptidic bond between Gly A1 and Leu A2 is $1.3 \AA$ ). We also noticed that Phe residues, oxidized to DOCH, were not involved in crosslinks, nor were they derivatized with ABS. In both cases this could be due to low accessibility of Phe residues which might belong to chains $\mathrm{B}$ involved in the formation of HMWO, in which only DOCH originated from Tyr is accessible for ABS derivatization. Moreover, in the case of cross-links it could be speculated that the oxidation of Tyr to DOCH (which requires the addition of only one oxygen atom), is kinetically favorable over the oxidation of Phe to DOCH (which requires two oxidation steps). This can potentially lead to a depletion of the nucleophiles available in the insulin molecule.

\section{CONCLUSIONS}

Oxidation is one important degradation process that proteins can undergo. In this work we highlighted the potential consequences of DOPA and DOCH formation and also illustrated how the knowledge of oxidation mechanisms can be utilized to investigate the mechanism of covalent aggregation. To this end, recombinant human insulin was used as a model: oxidation of aromatic amino acids residues, besides others, leads to $\alpha, \beta$ unsaturated carbonyl compounds, which are electron acceptors for Michael addition. These reactive groups, resulting from oxidation, not only can lead to covalent protein aggregation, as shown for insulin in this paper, but also may lead to cross-links between protein molecules and amino acids, which are typically present during cell culture and are often used as formulation excipients. This must be taken into consideration during production and formulation development of therapeutic proteins.

\section{ACKNOWLEDGMENTS \& DISCLOSURES}

The authors thank Dr. Nadya Galeva for performing MS measurements, Merck (Oss, The Netherlands) and The University of Kansas and the National Institutes of Health (PO1AG12993) for financial support, and Merck for providing insulin for this project, Leiden University Fund/Slingelands (LUF, 1111/19-4-11\O, Sl) and Nederlandse Stichting voor Farmacologische Wetenschappen (NSFW) for the travel grants to Riccardo Torosantucci.

Open Access This article is distributed under the terms of the Creative Commons Attribution License which permits any use, distribution, and reproduction in any medium, provided the original author(s) and the source are credited.

\section{REFERENCES}

1. Stadtman ER, Oliver CN. Metal-catalyzed oxidation of proteins. Physiological consequences. J Biol Chem. 1991;266:2005-8.

2. Sadineni V, Schöneich C. Selective oxidation of Zn2+-Insulin catalyzed by Cu2+. J Pharm Sci. 2007;96:1844-7.

3. Zhao F, Ghezzo-Schöneich E, Aced GI, Hong J, Milby T, Schöneich C. Metal-catalyzed oxidation of histidine in human growth hormone. Mechanism, isotope effects, and inhibition by a mild denaturing alcohol. J Biol Chem. 1997;272:9019-29.

4. Jenkins N. Modifications of therapeutic proteins: challenges and prospects. Cytotechnology. 2007;53:121-5.

5. Hermeling S, Schellekens H, Maas C, Gebbink MFBG, Crommelin DIA, Jiskoot W. Antibody response to aggregated human interferon alpha2b in wild-type and transgenic immune tolerant mice depends on type and level of aggregation. J Pharm Sci. 2006;95:1084-96.

6. Hermeling S, Aranha L, Damen JMA, Slijper M, Schellekens H, Crommelin DJA, Jiskoot W. Structural characterization and immunogenicity in wild-type and immune tolerant mice of degraded recombinant human interferon alpha2b. Pharm Res. 2005;22:1997-2006.

7. van Beers MM, Sauerborn M, Gilli F, Brinks V, Schellekens H, Jiskoot W. Oxidized and aggregated recombinant human 
interferon beta is immunogenic in human interferon beta transgenic mice. Pharm Res. 2011;28:2393-402.

8. Brownlee M. The pathobiology of diabetic complications: a unifying mechanism. Diabetes. 2005;54:1615-25.

9. Cheng RZ, Kawakishi S. Site-specific oxidation of histidineresidues in glycated insulin-mediated by $\mathrm{Cu} 2+$. Eur J Biochem. 1994:223:759-64.

10. Montes-Cortes DH, Hicks JJ, Ceballos-Reyes GM, GarciaSanchez JR, Medina-Navarro R, Olivares Corichi IM. Chemical and functional changes of human insulin by in vitro incubation with blood fromdiabetic patients in oxidative stress. Metabolism. 2010;59:935-42.

11. Gieseg SP, Simpson JA, Charlton TS, Duncan MW, Dean RT. Protein-bound 3,4-dihydroxyphenylalanine is a major reductant formed during hydroxyl radical damage to proteins. Biochemistry. 1993;32:4780-6.

12. Wright E, Scism-Bacon JL, Glass LC. Oxidative stress in type 2 diabetes: the role of fasting and postprandial glycaemia. Int J Clin Pract. 2006;60:308-14.

13. Torosantucci R, Kukrer B, Mero A, Van Winsen M, Tantipolphan $\mathrm{R}$, Jiskoot W. Plain and mono-pegylated recombinant human insulin exhibit similar stress-induced aggregation profiles. J Pharm Sci. 2011;100:2574-85.

14. Lovstad RA. Copper catalyzed oxidation of ascorbate (vitamin C). Inhibitory effect of catalase, superoxide dismutase, serum proteins (ceruloplasmin, albumin, apotransferrin) and amino acids. Int $\mathrm{J}$ Biochem. 1987;19:309-13.

15. Li SH, Nguyen TH, Schöneich C, Borchardt RT. Aggregation and precipitation of human relaxin induced by metal-catalyzed oxidation. Biochemistry-Us. 1995;34:5762-72.

16. Stadtman ER. Oxidation of free amino acids and amino acid residues in proteins by radiolysis and by metal-catalyzed reactions. Annu Rev Biochem. 1993;62:797-821.

17. Fu SL, Dean R, Southan M, Truscott R. The hydroxyl radical in lens nuclear cataractogenesis. J Biol Chem. 1998;273:28603-9.

18. Fu S, Davies MJ, Stocker R, Dean RT. Evidence for roles of radicals in protein oxidation in advanced human atherosclerotic plaque. Biochem J. 1998;333:519-25.

19. Sharov VS, Dremina ES, Pennington J, Killmer J, Asmus C, Thorson M, Hong SJ, Li X, Stobaugh JF, Schöneich C. Selective fluorogenic derivatization of 3-nitrotyrosine and 3.4 dihydroxyphenylalanine in peptides: a method designed for quantitative proteomic analysis. Methods Enzymol. 2008;441:19-32.

20. Sharov VS, Dremina ES, Galeva NA, Gerstenecker GS, Li X, Dobrowsky RT, Stobaugh JF, Schöneich C. Fluorogenic tagging of peptide and protein 3-nitrotyrosine with 4-(aminomethyl) benzenesulfonic acid for quantitative analysis of protein tyrosine nitration. Chromatographia. 2010;71:37-53.

21. Gallo-Rodriguez C, Ji XD, Melman N, Siegman BD, Sanders LH, Orlina J, Fischer B, Pu Q Olah ME, van Galen PJ, et al. Structureactivity relationships of N6-benzyladenosine-5'-uronamides as A3selective adenosine agonists. J Med Chem. 1994;37:636-46.

22. Brange J, Langkjaer L, Havelund S, Volund A. Chemical stability of insulin. 1. Hydrolitic degradation during storage of pharmaceutical preparation. Pharm Res. 1992;9:715-26.

23. Insulin. The United States Pharmacopeia Convention, Inc., Rockville, Maryland. 2002.

24. Insulin. Human, European Directorate for the Quality of Medicines (EDQM), Strasbourg, France. 2001

25. Giulivi C, Davies KJA. Dityrosine: a marker for oxidatively modified proteins and selective proteolysis. Methods Enzymol. 1994;233:363-71.

26. Ikehata K, Duzhak TG, Galeva NA, Ji T, Koen YM, Hanzlik RP. Protein targets of reactive of thiobenzamide in rat liver in vivo. Chem Res Toxicol. 2008;21:1432-42.
27. Xu H, Freitas MA. MassMatrix: a database search program for rapid characterization of proteins and peptides from tandem mass spectrometry data. Proteomics. 2009;9:1548-55.

28. Xu H, Freitas MA. A mass accuracy sensitive probability based scoring algorithm for database searching of tandem mass spectrometry data. BMC Bioinformatics. 2007;8:133.

29. Xu H, Yang L, Freitas MA. A robust linear regression based algorithm for automated evaluation of peptide identifications from shotgun proteomics by use of reversed-phase liquid chromatographyretention time. BMC Bioinformatics. 2008;9:347.

30. Xu H, Zhang L, Freitas MA. Identification and characterization of disulfide bonds in proteins and peptides from tandem MS data by use of the MassMatrix MS/MS search engine. J Proteome Res. 2008;7:138-44.

31. Tantipolphan R, Romeijn S, Engelsman J, Torosantucci R, Rasmussen $\mathrm{T}$, Jiskoot W. Elution behavior of insulin on high-performance size exclusion chromatography at neutral $\mathrm{pH}$. J Pharm Biomed Anal. 2010;52:195-202.

32. Tokoroyama, T. Discovery of the Michael Reaction IN MEMORIAM. European J. Org. Chem. 2010;2009-2016.

33. Guedes S, Vitorino R, Domingues MR, Amado F, Domingues P. Oxidative modifications in glycated insulin. Anal Bioanal Chem. 2010;397:1985-95.

34. Roepstorff P, Fohlman J. Proposal for a common nomenclature for sequence ions in mass spectra of peptides. Biomed Mass Spectrom. 1984;11:601.

35. Paizs B, Suhai S. Fragmentation pathways of protonated peptides. Mass Spectrom Rev. 2005;24:508-48.

36. Taylor GM, Wang W. Histidinoalanine: a crosslinking amino acid. Tetrahedron. 2007;63:9033-47.

37. Kato Y, Kitamoto N, Kawai Y, Osawa T. The hydrogen peroxide system, but not other metal-catalyzed oxidation systems, produces protein-bound dityrosine. Free Radic Biol Med. 2001;31:624-32.

38. Hawkins CL, Davies MJ. Generation and propagation of radical reaction. Biochim Biophys Acta. 2001;1504:196-219.

39. Chin J. Developing artificial hydrolytic metalloenzymes by a unified mechanistic approach. Accounts Chem Res. 1991;24:145-52.

40. Requena JR, Groth D, Legname G, Stadtman ER, Prusiner SB, Levine RL. Copper-catalyzed oxidation of the recombinant $\mathrm{SHa}$ (29-231) prion protein. Proc Natl Acad Sci. 2001;98:7170-5.

41. Rakhit R, Gunningham P, Furtos-Matei A, Dahan S, Qi XF, Crow JP, Cashman NR, Kondejewski LH, Chakrabartty A. Oxidation-induced misfolding and aggregation of superoxide dismutase and its implications for amyotrophic lateral sclerosis. J Biol Chem. 2002:277:47551-6.

42. Luo QZ, Joubert MK, Stevenson R, Ketchem RR, Narhi LO, Wypych J. Chemical modifications in therapeutic protein aggregates generated under different stress conditions. J Biol Chem. 2011;286:25134-44.

43. Taylor SW, Fahy E, Murray J, Capaldi RA, Ghosh SS. Oxidative post-translational modification of tryptophan residues in cardiac mitochondrial proteins. J Biol Chem. 2003;278:19587-90.

44. Kim YH, Berry AH, Spencer DS, Stites WE. Comparing the effect on protein stability of methionine oxidation versus mutagenesis: steps toward engineering oxidative resistance in proteins. Protein Eng. 2001;14:343-7.

45. Brange J, Langkjoer L. Insulin structure and stability. Pharm Biotechnol. 1993;5:315-50.

46. Guex N, Diemand A, Peitsch MC. Protein modelling for all. Trends Biochem Sci. 1999;24:364-7.

47. Guex N, Peitsch MC. SWISS-MODEL and the Swiss-PdbViewer: an environment for comparative protein modeling. Electrophoresis. 1997;18:2714-23. 